\title{
Treatment of Cardiovascular Disease by Traditional Chinese Medicine against Pregnane $X$ Receptor
}

\author{
Kuen-Bao Chen, ${ }^{1,2,3}$ Hsin-Yi Chen, ${ }^{2}$ Kuan-Chung Chen, ${ }^{4}$ and Calvin Yu-Chian Chen ${ }^{1,2,5,6}$ \\ ${ }^{1}$ School of Medicine, College of Medicine, China Medical University, Taichung 40402, Taiwan \\ ${ }^{2}$ Department of Biomedical Informatics, Asia University, Taichung 41354, Taiwan \\ ${ }^{3}$ Department of Anesthesiology, China Medical University Hospital, Taichung 40447, Taiwan \\ ${ }^{4}$ School of Pharmacy, China Medical University, Taichung 40402, Taiwan \\ ${ }^{5}$ Research Center for Chinese Medicine \& Acupuncture, China Medical University, Taichung 40402, Taiwan \\ ${ }^{6}$ Human Genetic Center, Department of Medical Research, China Medical University Hospital, Taichung, Taiwan \\ Correspondence should be addressed to Calvin Yu-Chian Chen; ycc929@MIT.edu
}

Received 19 February 2014; Accepted 5 March 2014; Published 22 June 2014

Academic Editor: Chung Y. Hsu

Copyright (C) 2014 Kuen-Bao Chen et al. This is an open access article distributed under the Creative Commons Attribution License, which permits unrestricted use, distribution, and reproduction in any medium, provided the original work is properly cited.

Recently, cardiovascular disease, also known as loop circulatory system diseases or disorders, is one of the serious diseases including heart disease, stroke, atherosclerosis, myocardial infarction, hypertension, hypotension, and thrombosis. Human pregnane $\mathrm{X}$ receptor, PXR, plays a crucial role in exogenous and endobiotic metabolism for rabbit, rat, mouse, and human. The PXR activation can protect the blood vessels from damage of hazardous substances. In this study we aim to investigate the potent lead compounds as PXR receptor agonist against cardiovascular disease. To improve drug development of TCM compounds, we aim to investigate the potent lead compounds as PXR agonists from the TCM compounds in TCM Database@Taiwan. The top three TCM compounds, bis(4-hydroxybenzyl) ether mono- $\beta$-D-glucopyranoside (BEMG), ixerisoside, and tangshenoside II, have displayed higher potent binding affinities than the positive control, PNU-142721, in the docking simulation. After MD simulations, which can optimize the result of docking simulation and validate the stability of $\mathrm{H}$-bonds between each ligand and PXR protein under dynamic conditions, top TCM compounds, BEMG and tangshenoside II, maintain most of interactions with PXR protein, which keep the ligand binding stable in the binding domain. Hence, we propose BEMG and tangshenoside II as potential lead compounds for further study in drug development process with the PXR protein.

\section{Introduction}

Recently, cardiovascular disease, also known as loop circulatory system diseases or disorders, is one of the serious diseases including heart disease, stroke, atherosclerosis, myocardial infarction, hypertension, hypotension, and thrombosis. It is the top leading cause of death in the United States and most European countries. More than 83.6 million Americans have the cardiovascular problems; the patients of cardiovascular disease in other Western countries are also growing yearly [1]. Family history, obesity, latent diseases, such as diabetes, gout and kidney disease, and bad habits, diet, the environment of toxic substances, and drugs are the risk factors for cardiovascular disease [2-4]. Environmental pollution and chemicals also promote the occurrence of blood vessel function disorders and cardiovascular diseases. We should consider how to regulate and protect the blood vessels [5].

Nowadays, many distinct mechanisms of diseases have been identified $[6,7]$ to determine the potential target proteins for drug design against each disease [8-11]. Human pregnane $\mathrm{X}$ receptor, $\mathrm{PXR}$, plays a crucial role in exogenous metabolism for rabbit, rat, mouse, and human [2-5]. Some studies indicate that PXR also plays an important role in endobiotic metabolism for rabbit, rat, mouse, and human [12-22]. Activated PXR binds to response elements in the promoters and upregulates the transcription of Phases I and II drug-metabolizing enzymes, for example, glutathione 


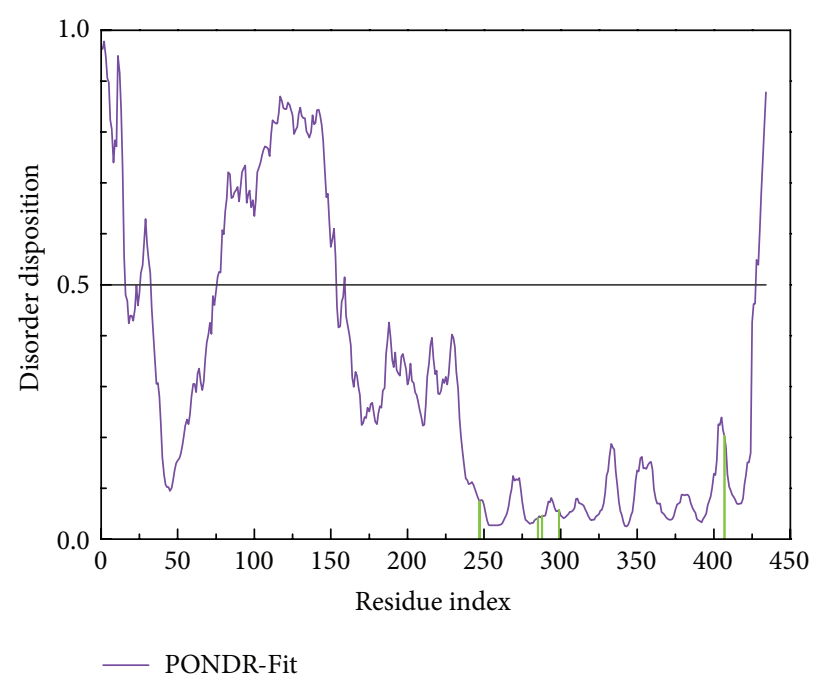

FIGURE 1: Disordered disposition predicted by PONDR-Fit.

S-transferases (GSTs) and cytochrome P450 (CYP)s, and transporters, for example, multidrug resistance protein 1 (MDR1) [12,13]. It provides a mechanism for the blood vessels to protect itself and the underlying tissue under exogenous and endobiotic insults [14].

The human pregnane $\mathrm{X}$ receptor, $\mathrm{PXR}$ (NR1I2, also known as PAR or SXR), is a key transcription factor gene expression and regulation of CYP3A. It is combined by DNA binding domain (DBD) and ligand binding domain (LBD) [19-21]. It is composed of three $\alpha$-helices and five $\beta$-folds formed around globular ligand binding cavity [22]. PXR can be activated by variant ligands, including drug [12], endogenous compounds [12, 23], and environmental contaminants [24]. PXR has a similar protective effect in the vessel and in liver, which can stop the liquid, the solute, and the cells in the vessel wall. Therefore, the PXR activation can protect the blood vessels from damage of hazardous substances. In this study, we aim to investigate the potent lead compounds as PXR receptor agonist against cardiovascular disease.

Recently, in silico researches have been broadly used in the drug design [25-29]. Many compounds extracted from traditional Chinese medicine (TCM) had been determined as potential lead compounds for many different diseases, such as stroke [30-32], tumors [33-36], inflammation [37], metabolic syndrome [38-40], viral infection $[41,42]$, and some disorders [43-45]. As structural disordered amino acids in the binding domain of protein may affect the ligand binding with target protein and induce side effect [46, 47], the disordered amino acids of PXR protein were predicted before virtual screening. For TCM compounds filtered by virtual screening, the interactions of the docking poses in the docking simulation may be modified under dynamic conditions. We employed the molecular dynamics (MD) simulations to validate the stability of each docking pose. In addition, the biological activities of potential TCM candidates were predicted by three distinct models.

\section{Materials and Methods}

2.1. Data Collection. The X-ray crystallography structure of the human pregnane $\mathrm{X}$ receptor $(\mathrm{PXR})$ was downloaded from RCSB Protein Data Bank with PDB ID 3R8D [48]. The disordered amino acids of PXR protein were predicted using PONDR-Fit [49] protocol with the sequence of PXR protein from Swiss-Prot (UniProtKB: O75469). The PXR protein has protonated the final structure of protein with Chemistry at HARvard Macromolecular Mechanics (CHARMM) force field [50] and removed crystal water using Prepare Protein module in Discovery Studio 2.5 (DS 2.5). The binding domain was defined by the volume of the cocrystallized anti-HIV drug, PNU-142721. TCM compounds from TCM Database@Taiwan [51] have protonated the final structure and have been filtered by Lipinski et al.s Rule of Five [52] using Prepare Ligand module in DS 2.5.

2.2. Docking Simulation. The prepared TCM compounds have been docked in the binding domain of PXR protein using LigandFit protocol [53] in DS 2.5 which docks ligands into the binding domain using a shape filter and MonteCarlo ligand conformation generation and then optionally minimized with CHARMM force field [50] and rejected the similar poses by the clustering of saved docking pose. The consensus scores were calculated using the properties of PLP1, -PLP2, -PMF, -PMF04, dock score, Jain, LigScore1 Dreiding, LigScore2 Dreiding, ligand internal energy, Ludi 1, Ludi 2, and Ludi 3. 


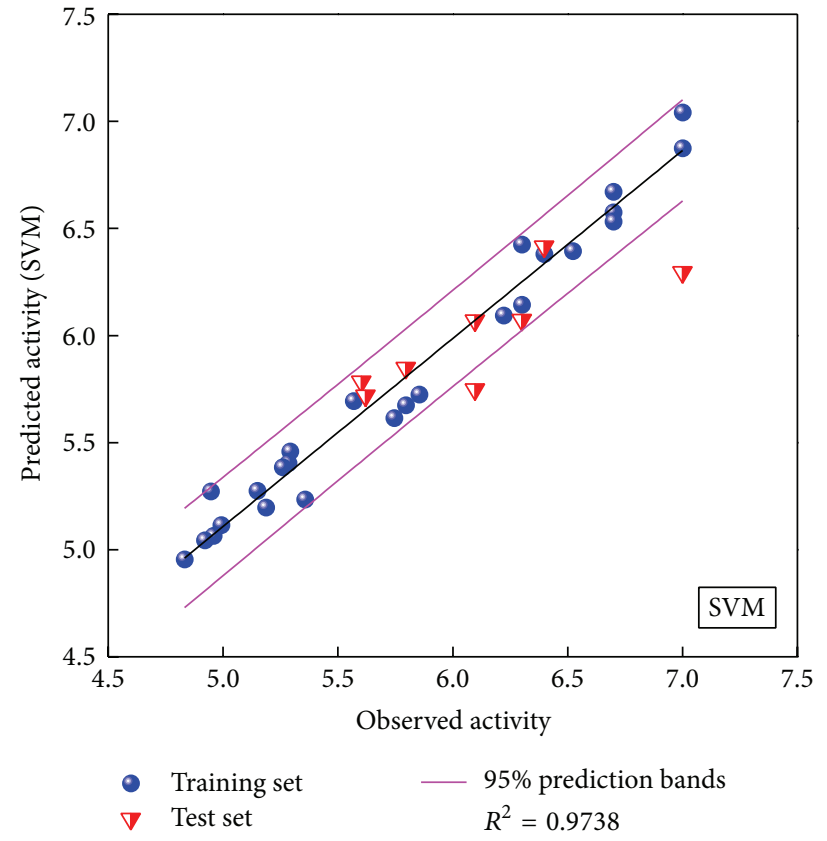

(a)

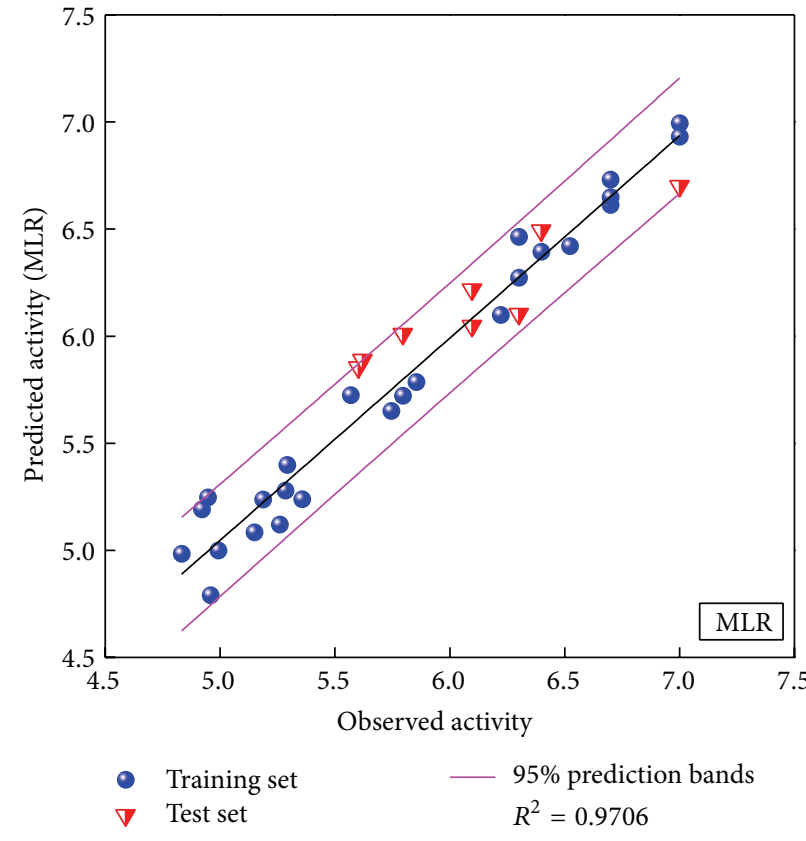

(b)

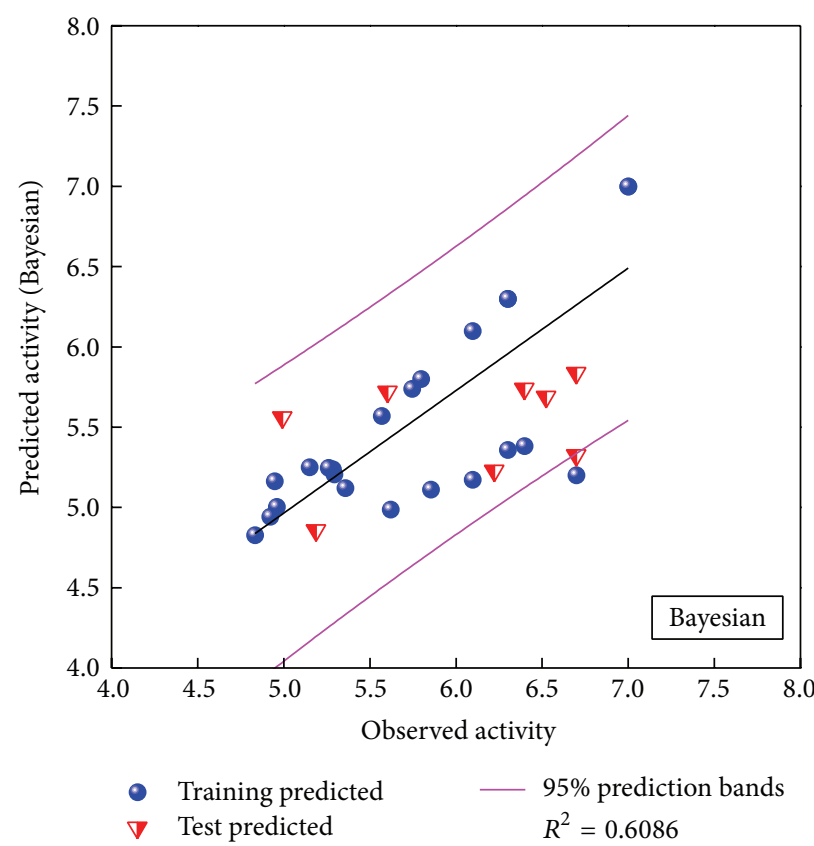

(c)

FIGURE 2: Comparative plots of observed versus predicted activity for (a) SVM, (b) MLR, and (c) BNT models.

2.3. Biological Activity Prediction. Three distinct prediction models, multiple linear regression (MLR), support vector machine (SVM), and Bayes network toolbox (BNT) models, were employed to predict the biological activity for the TCM compounds using the $\mathrm{pEC}_{50}\left(\log \left(1 / \mathrm{EC}_{50}\right)\right)$ value of 25 compounds out of 33 PXR agonists [54]. The suitable molecular descriptors for constructing the prediction models were selected using genetic function approximation module [55] in DS 2.5, and the protocol estimates the fitness of individual model using square correlation coefficient $\left(R^{2}\right)$. The prediction models have also been validated by cross validation test. In addition, MLR and BNT models were performed using MATLAB, and SVM model was performed using LibSVM developed by Chang and Lin [56]. 
<smiles>CCCCOC(C)(C)CCCOc1ccc(O[C@@H]2O[C@H](CO)[C@@H](O)[C@H](O)[C@H]2O)cc1</smiles>

(a)

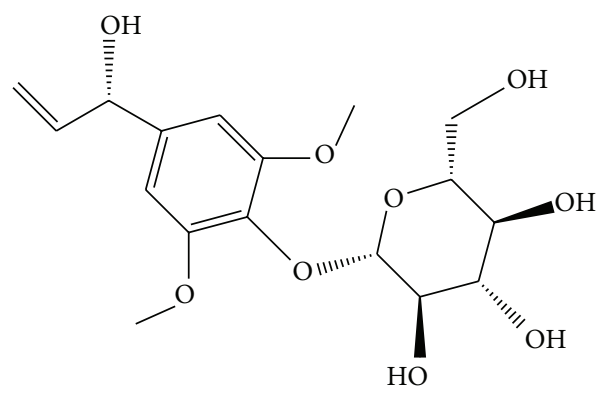

Tangshenoside II

(c)<smiles>C=C1C(=O)O[C@H]2[C@H]1C[C@@H](O[C@@H]1O[C@H](CO)[C@@H](O)[C@H](O)[C@H]1O)C(=C)[C@@H]1CCC(=C)[C@H]21</smiles>

(b)<smiles>C[C@H](Sc1nc(N)cc(Cl)n1)c1cc2ccoc2cn1</smiles>

PNU-142721

(d)

FIGURE 3: Chemical scaffold of control and the top three candidates: (a) bis(4-hydroxybenzyl) ether mono-beta-D-glucopyranoside (BEMG), (b) ixerisoside, (c) tangshenoside II, and (d) PNU-142721.

2.4. Molecular Dynamics (MD) Simulation. For each docking pose in the dock simulation, the protein-ligand complex has been simulated under dynamic conditions with classical molecular dynamics theory using Gromacs 4.5.5 [57]. The topology and parameters for PXR protein with CHARMM27 force field and each ligand were provided using pdb2gmx protocol in Gromacs and SwissParam program [58], respectively. A cubic box is performed with the box edge approximate $1.2 \mathrm{~nm}$ from the molecules periphery and solvated using TIP3P water model neutralized by $0.145 \mathrm{M} \mathrm{NaCl}$ model using Gromacs. Then the steepest descent [59] was employed to remove bad van der Waals contacts with a maximum of 5,000 steps. In equilibration section, the position-restrained molecular dynamics simulation was employed using linear constraint algorithm, NVT equilibration, Berendsen weak thermal coupling method, and particle mesh Ewald method.

A total of $40 \mathrm{~ns}$ production simulation with time step in unit of $2 \mathrm{fs}$ was performed using particle mesh Ewald (PME) option and NPT ensembles. A series of protocols in Gromacs, such as g_rms, g_gyrate, g_msd, g_sas, g_energy, g_rmsf, and do_dssp, was employed to analyze the MD trajectories.

\section{Results and Discussion}

3.1. Disordered Protein Prediction. The disordered disposition for the sequence of PXR protein from Swiss-Prot (UniProtKB: O75469) predicted by PONDR-Fit was illustrated in Figure 1. As the residues in the binding domain do not lie in the disordered region, the binding domain of PXR protein has a stable structure in protein folding.

3.2. Biological Activity Prediction. GFA (genetic functional analysis) protocol in DS 2.5 was employed with 204 descriptors to determine the ten optimum molecular descriptors for constructing prediction models with 25 compounds of training set. The selected descriptors were ES_Sum_dNH, ES_Sum_ssNH, ES_Sum_sssN, ES_Count_aaCH, ES_Count_ ssNH, Num_RingBonds, Molecular_PolarSASA, IAC_Total, Jurs_DPSA_3, and Jurs_PPSA_1. According to these selected descriptors, the functional formula of MLR model was constructed as follows:

$$
\begin{aligned}
\mathrm{pEC}_{50}= & -1.24629-0.44990 \times \mathrm{ES} \_S u m \_d N H \\
& +1.29360 \times \text { ES_Sum_ssNH }
\end{aligned}
$$




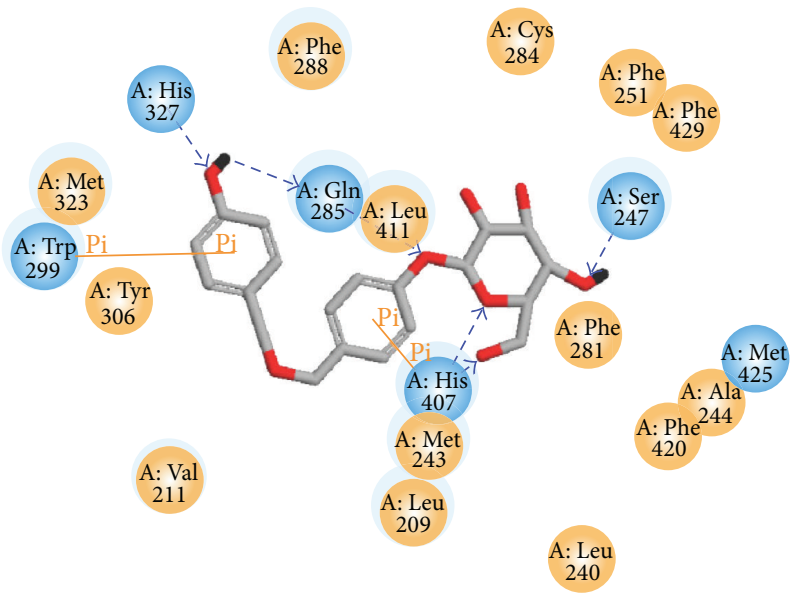

(a)

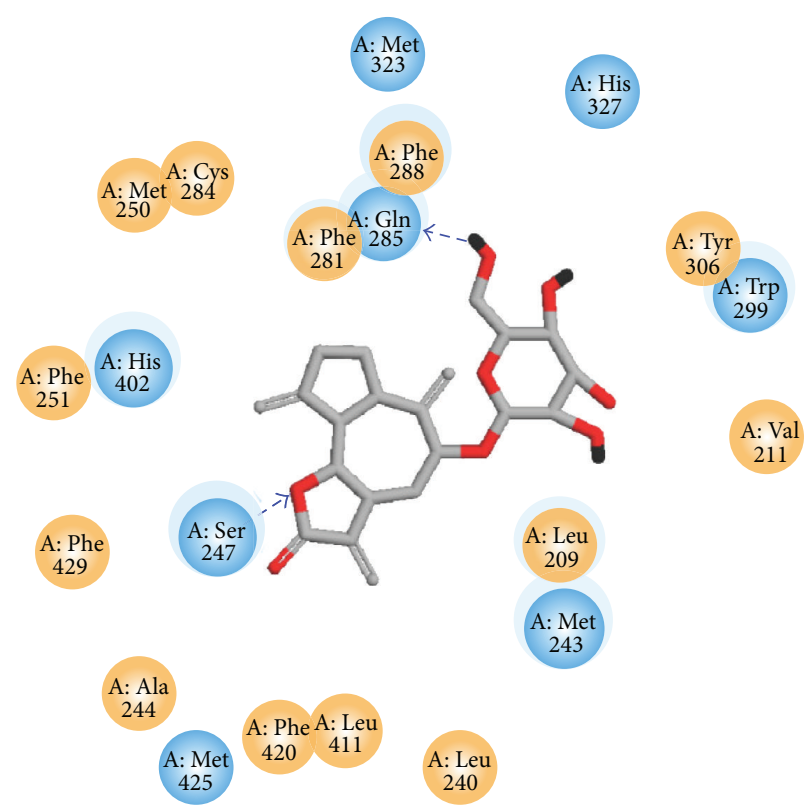

(b)

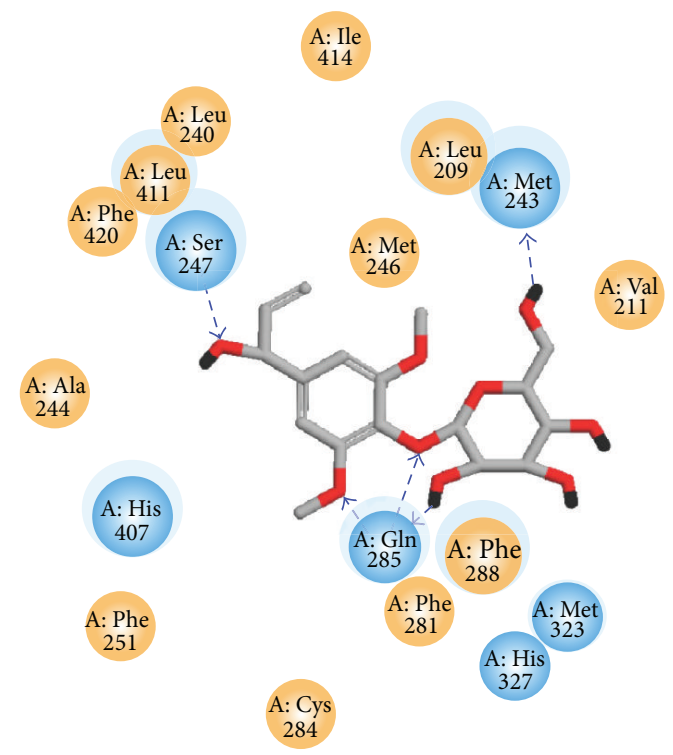

(c)

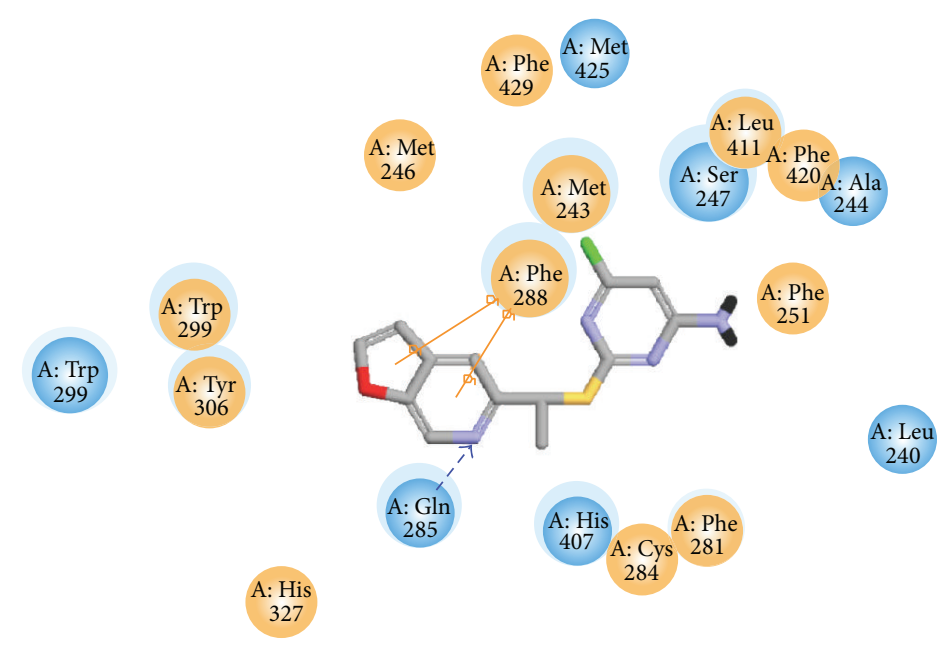

(d)

FIGURE 4: Docking pose of PXR complex with (a) BEMG, (b) ixerisoside, (c) tangshenoside II, and (d) PNU-142721.

$+0.65592 \times$ ES_Sum_sssN

- $0.28544 \times$ ES_Count_aaCH

$-2.05864 \times$ ES_Count_ssNH

$+0.16557 \times$ Num_RingBonds

$+0.01283 \times$ Molecular_PolarSASA

$-0.11968 \times$ IAC_Total $+0.05874 \times$ Jurs_DPSA_3

$+0.00872 \times$ Jurs_PPSA_1.
The SVM and BNT models were also constructed with the identical training set and descriptors. The correlation of predicted and observed activities shown in Figure 2 illustrates the correlation trend and 95\% prediction bands for each prediction model. The square correlation coefficients $\left(R^{2}\right)$ of training set for SVM, MLR, and BNT models are 0.9738, 0.9706 , and 0.6086 , respectively. These prediction models are acceptable for predicting activity of PXR protein.

3.3. Docking Simulation. According to the experimental results (Table 1), the consensus score, dock score, H-bond forming residues, $\mathrm{H}$-bond quantity, and the predicted activities by SVM, MLR, and BNT models are used to 


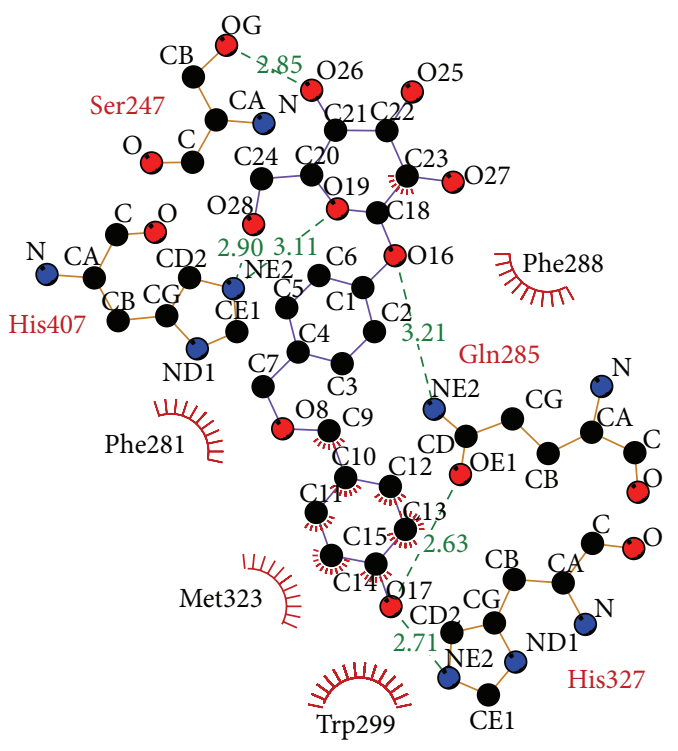

(a)

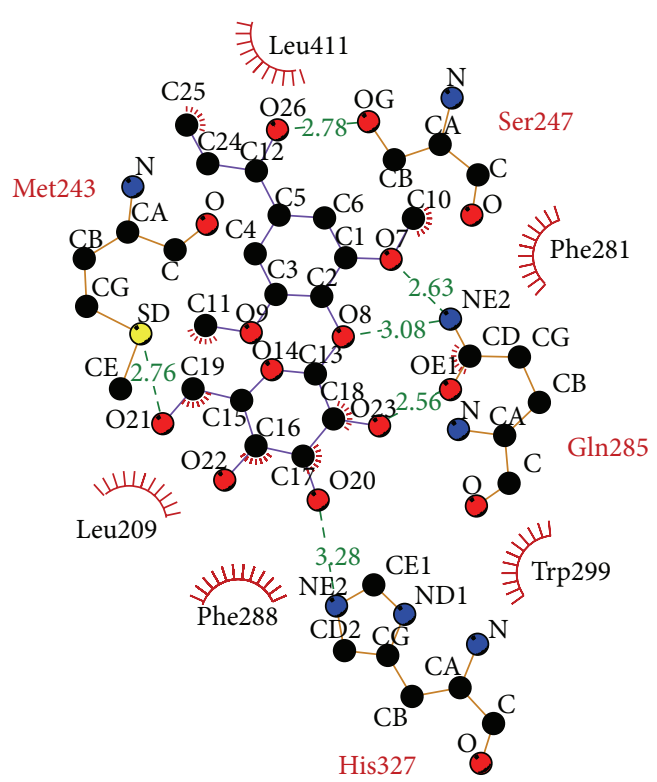

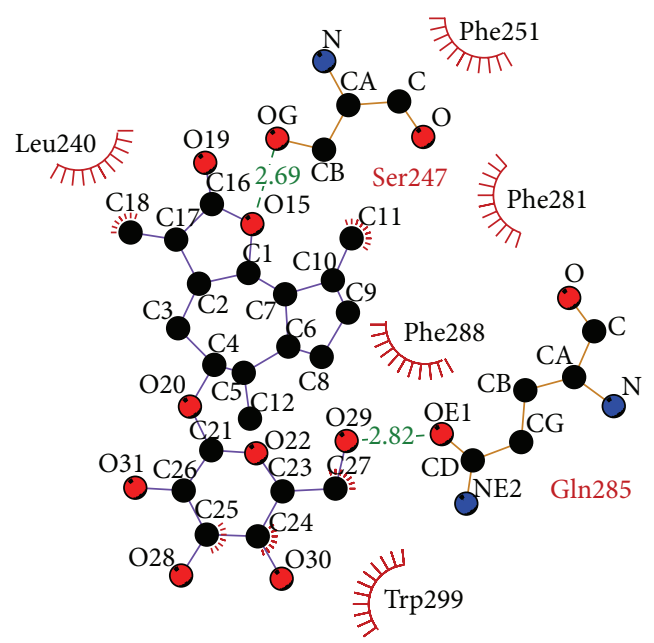

(b)

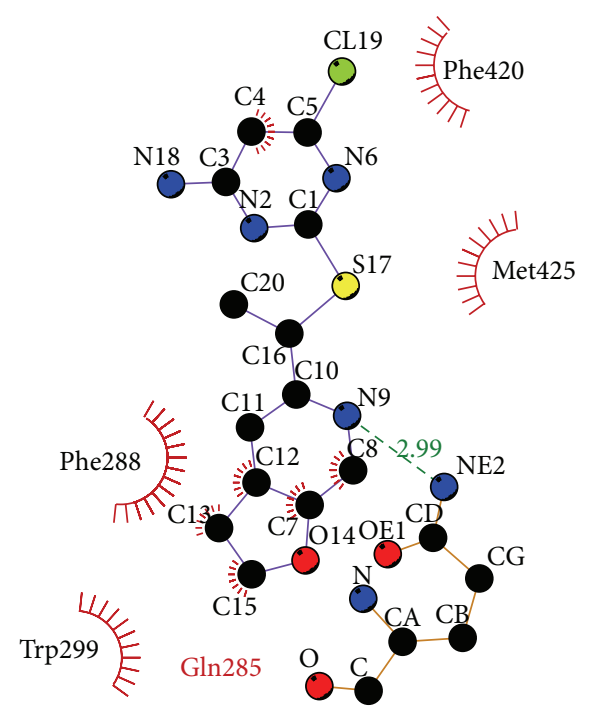

His53

$\lambda \pi \pi^{-1}$ Nonligand residues involved in hydrophobic contact(s)

Corresponding atoms involved in hydrophobic contact(s)

(d)

FIGURE 5: Docking pose of PXR complex with (a) BEMG, (b) ixerisoside, (c) tangshenoside II, and (d) PNU-142721 drawn by LigPlot program.

rank the top 20 TCM compounds. For the top three TCM compounds, bis(4-hydroxybenzyl) ether mono- $\beta$-Dglucopyranoside (BEMG), ixerisoside, and tangshenoside II, BEMG was extracted from Gastrodia elata [60], which have been indicated the effect of reducing blood pressure, increasing the heart, cerebral blood flow, and reducing cerebral vascular resistance $[61,62]$. Ixerisoside was extracted from Cichorium intybus [63], which can improve diabetes [64] and clear toxins in the liver [65]. Tangshenoside II was extracted from root of Codonopsis tangshen [66], which has excitatory effects for nervous system, and can enhance the body resistance; expansion of peripheral vascular and blood pressure, and inhibit the pressor effect of epinephrine, regulate gastrointestinal motility, anti-ulcer, inhibition of gastric acid secretion, reducing the activity of pepsin, raise leukocyte level declined after chemotherapy and radiation. The chemical scaffold top TCM compounds and PNU-142721 are illustrated in Figure 3. According to the docking poses 

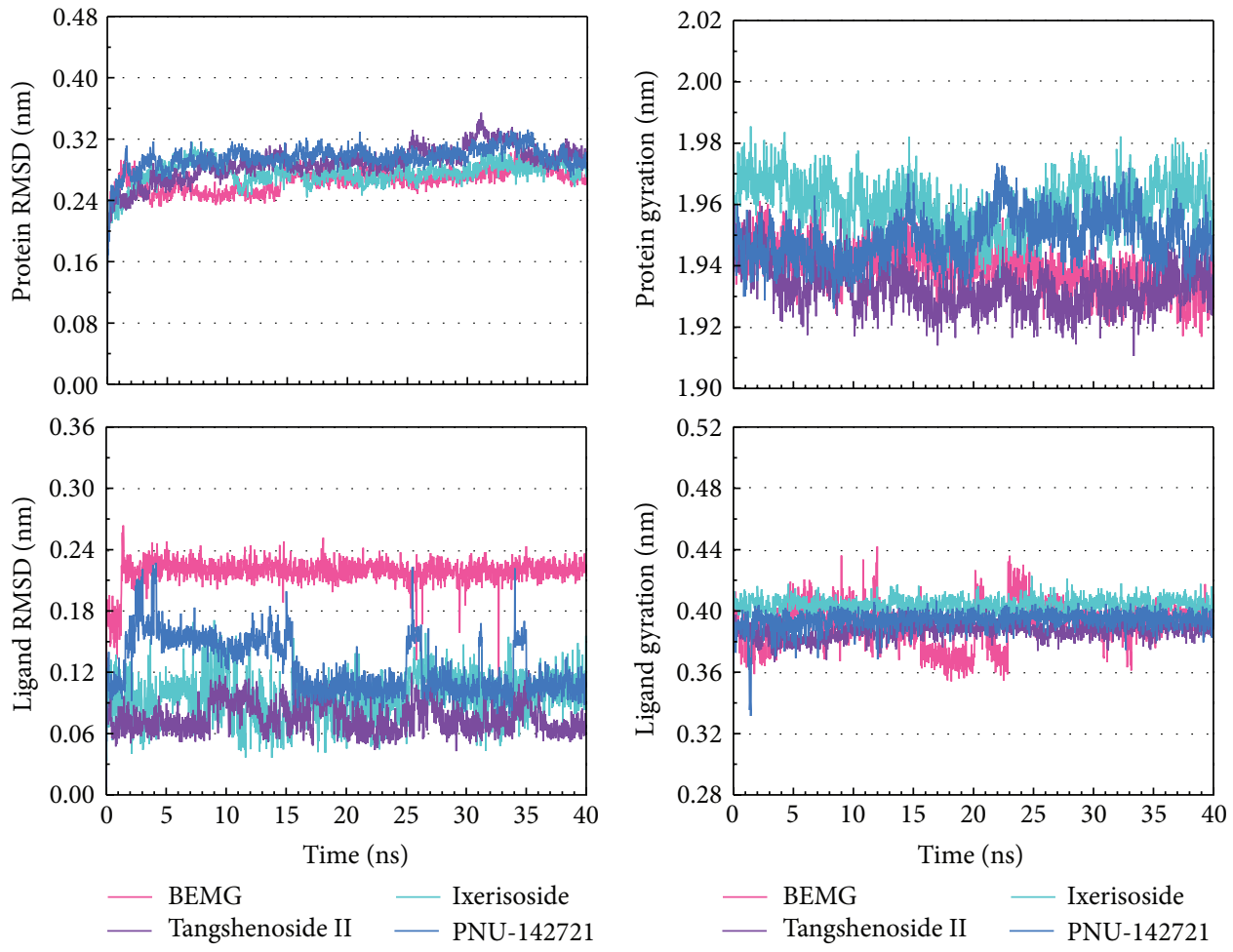

(a)

(b)
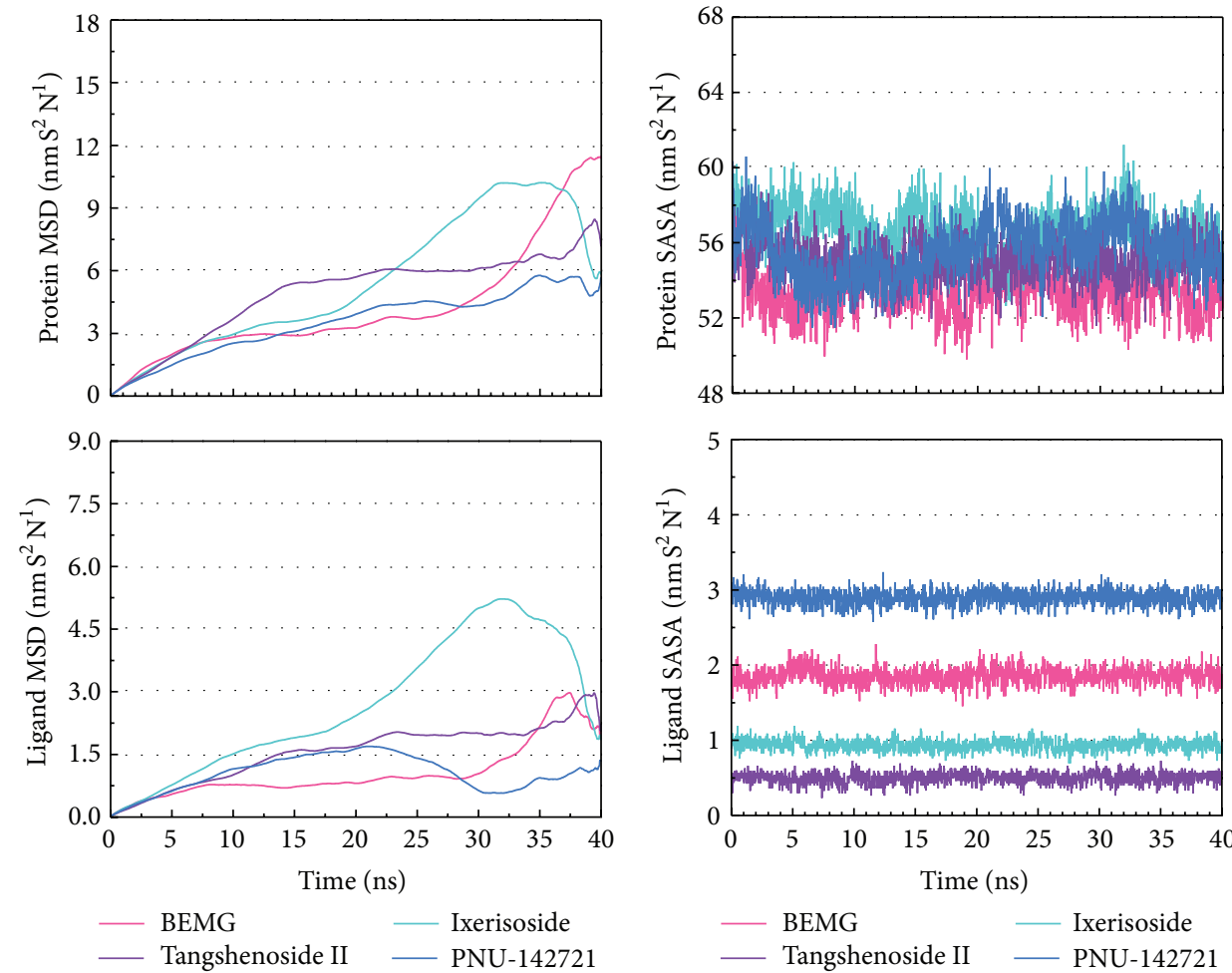

(c)

(d)

FIGURE 6: Analysis of MD trajectories generated by Gromacs: (a) root-mean-square deviations (RMSDs), (b) radii of gyration, (c) mean square deviation (MSD), and (d) total solvent accessible surface area (SASA). 


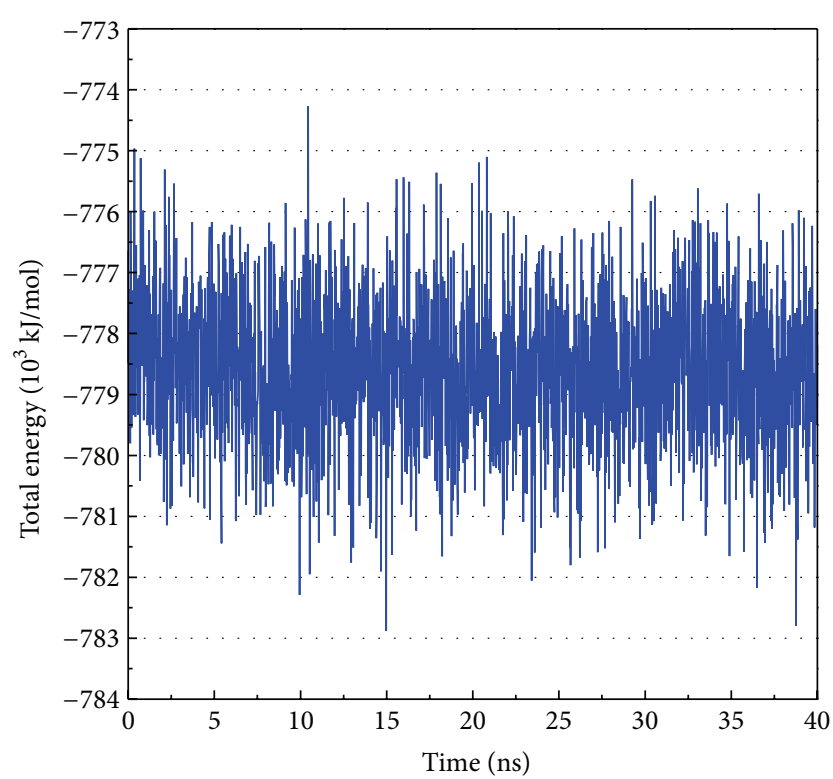

(a)

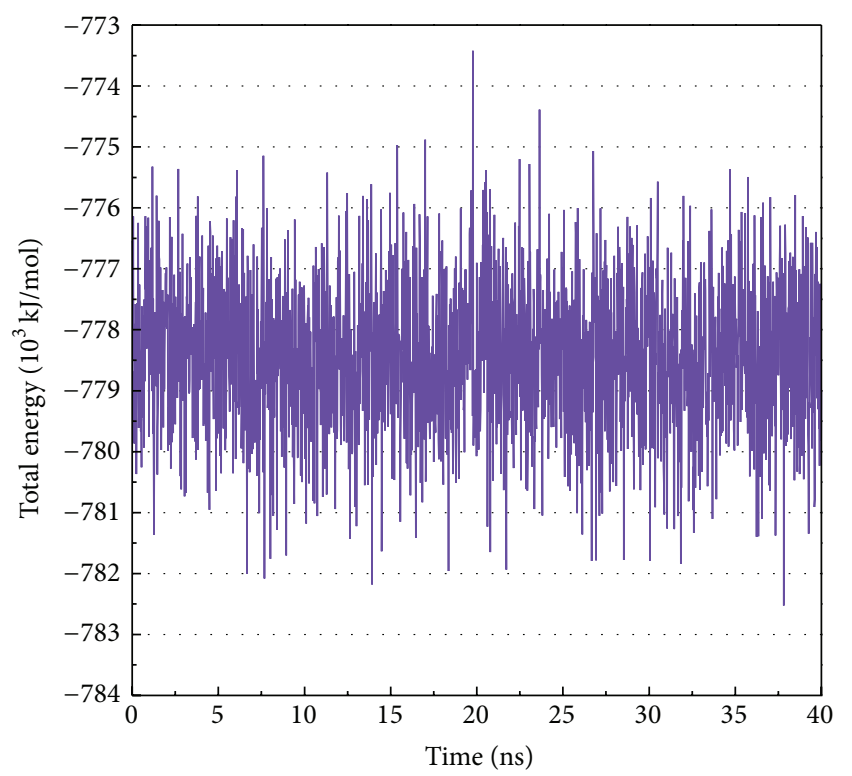

(c)

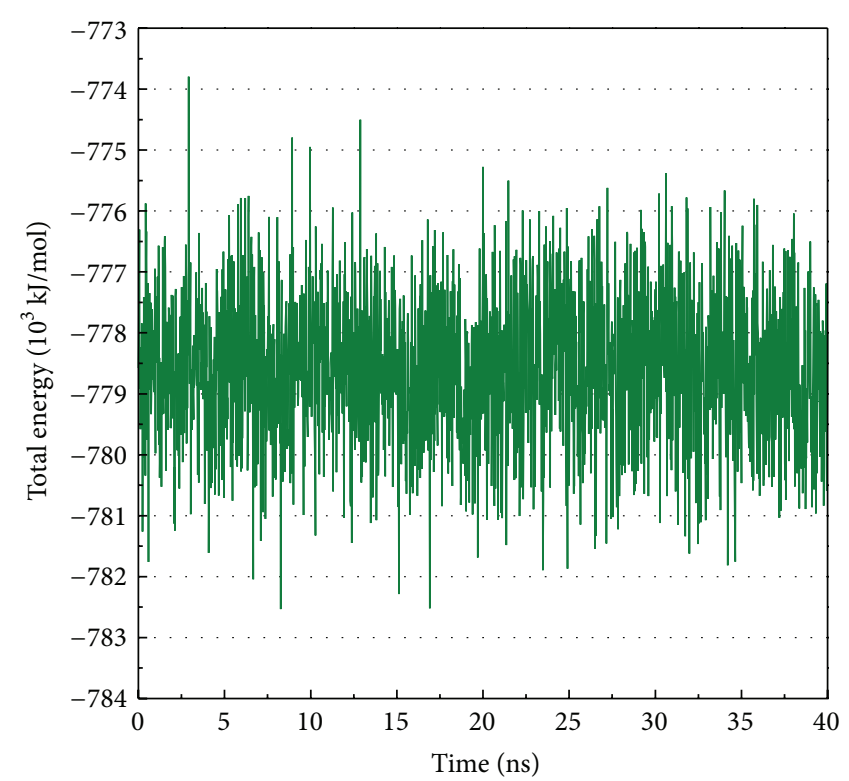

(b)

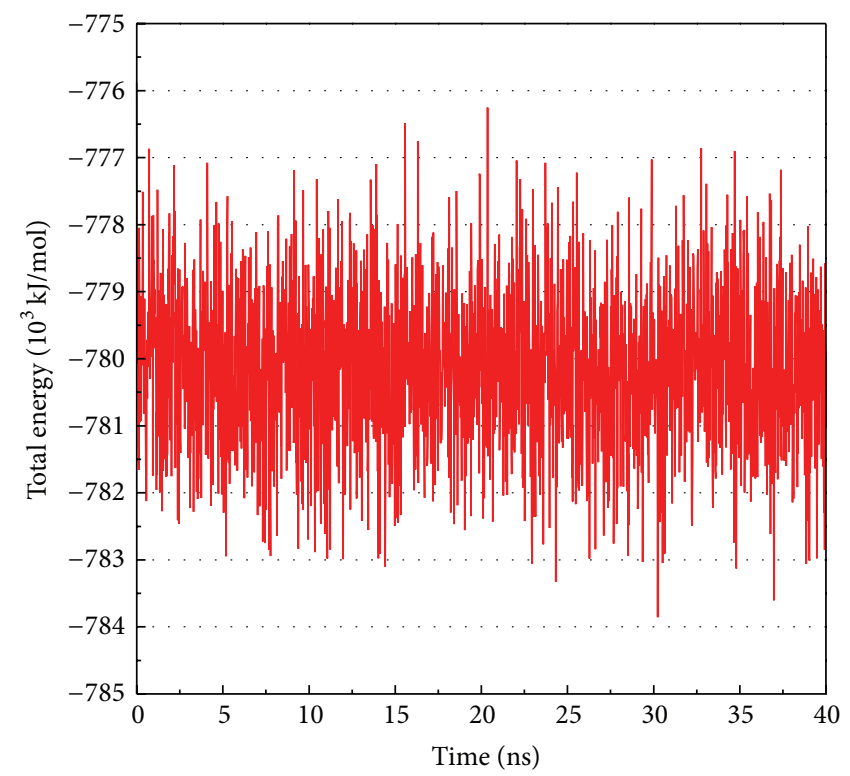

(d)

FIgure 7: Total energy of PXR complex with (a) BEMG, (b) ixerisoside, (c) tangshenoside II, and (d) PNU-142721.

in Figures 4 and 5, the top three candidate compounds and control have hydrogen bonds (H-bonds) with the common amino acid Gln285 exist. The top three candidate compounds have H-bonds with Ser247. In addition, BEMG still produces hydrogen bonds with His327 and His407 and generates $\pi$ bond with His407 and Trp299. Tangshenoside II will produce additional hydrogen bond with Met243, as well as PNU-142721 will produce $\pi$ bond with Phe288. Figure 5 illustrates the hydrophobic contacts between each compound and residues in the binding domain. The top three candidate compounds and control have hydrophobic contacts with common residues Phe288 and Trp299, and all TCM compounds have hydrophobic contacts with residue Phe281. The docking results indicate that the top three TCM candidate compounds have higher binding affinities than control. In addition, they have $\mathrm{H}$-bonds with key residues Ser 247 and Gln285 and hydrophobic contacts with key residues Trp299 and Phe288.

3.4. Molecular Dynamics Simulation. MD simulation was employed to validate the stability of interactions between PXR protein and each compound. Root-mean-square deviation (RMSD) illustrated the atomic fluctuations during MD simulation in Figure 6(a). Protein RMSD displays the 


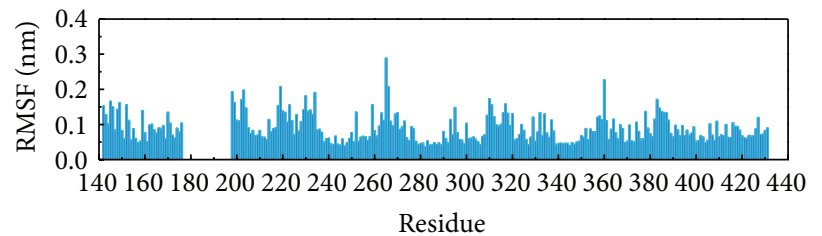

(a)

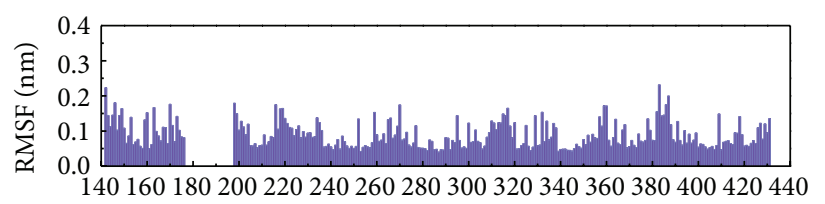
Residue

(c)

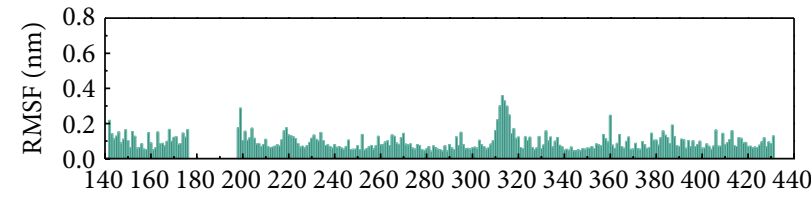
Residue

(b)

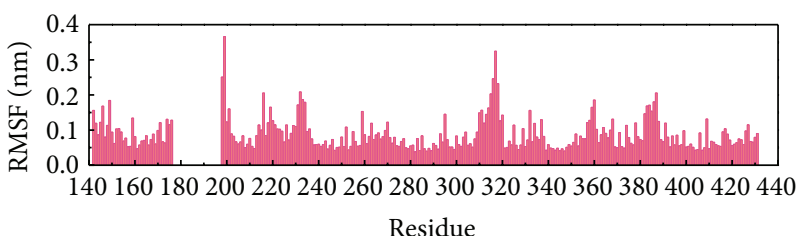

(d)

FIGURE 8: Root mean square fluctuation (RMSF) for residues in PXR complex with (a) BEMG, (b) ixerisoside, (c) tangshenoside II, and (d) PNU-142721 over 35-40 ns MD simulation.

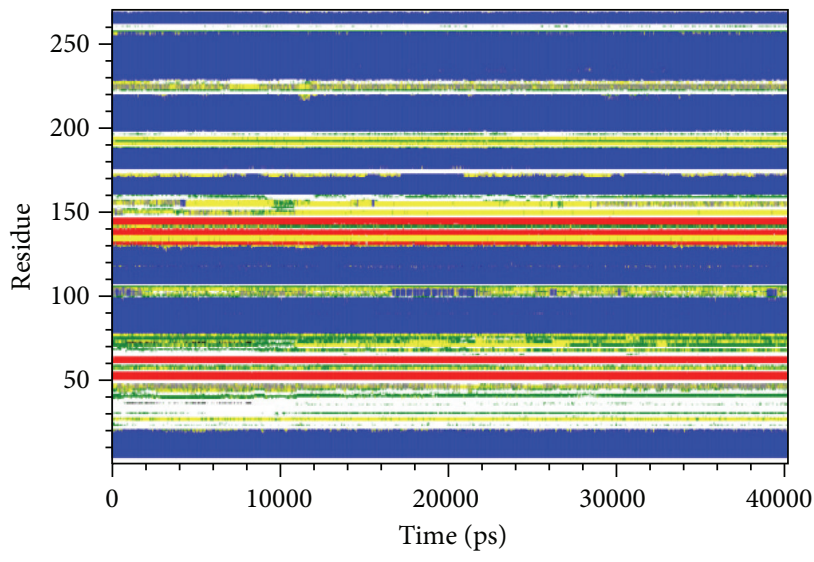

(a)

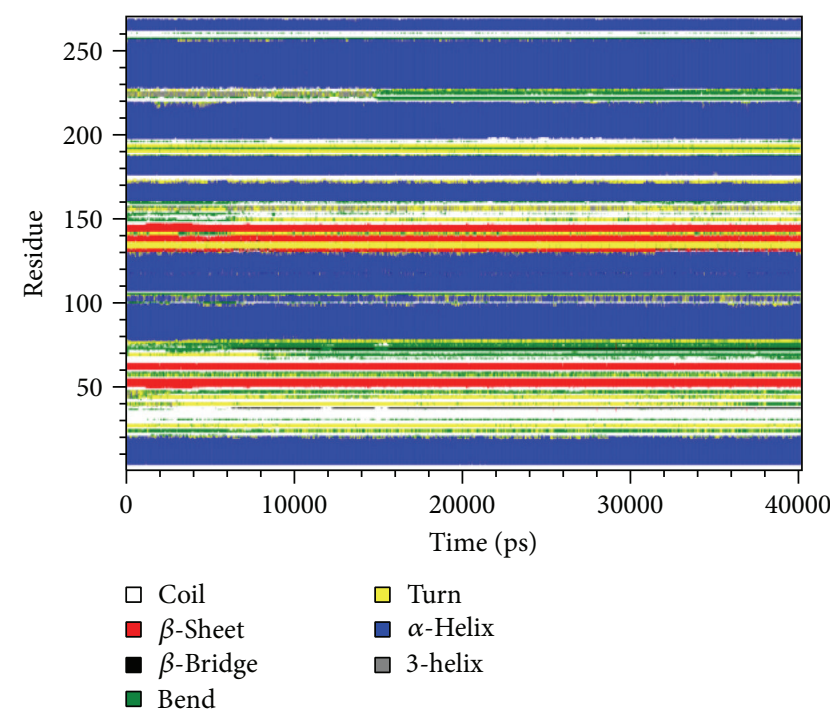

(c)

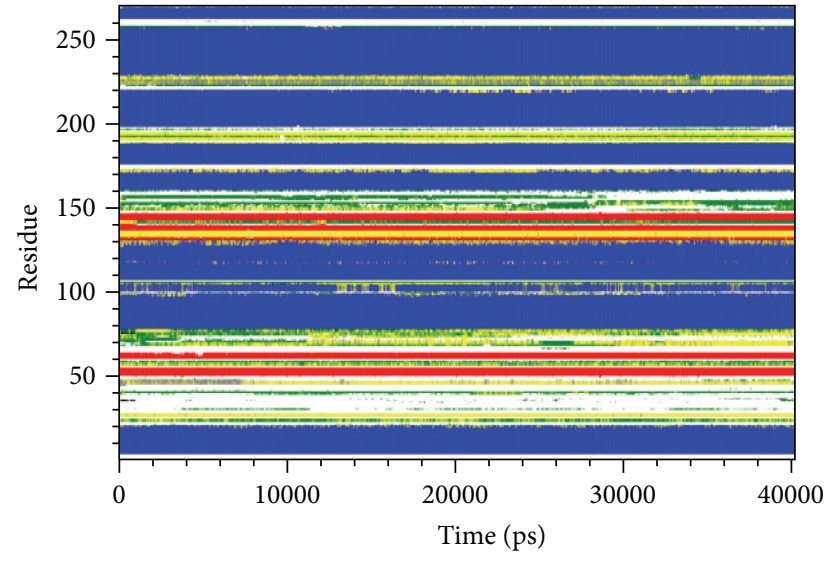

(b)

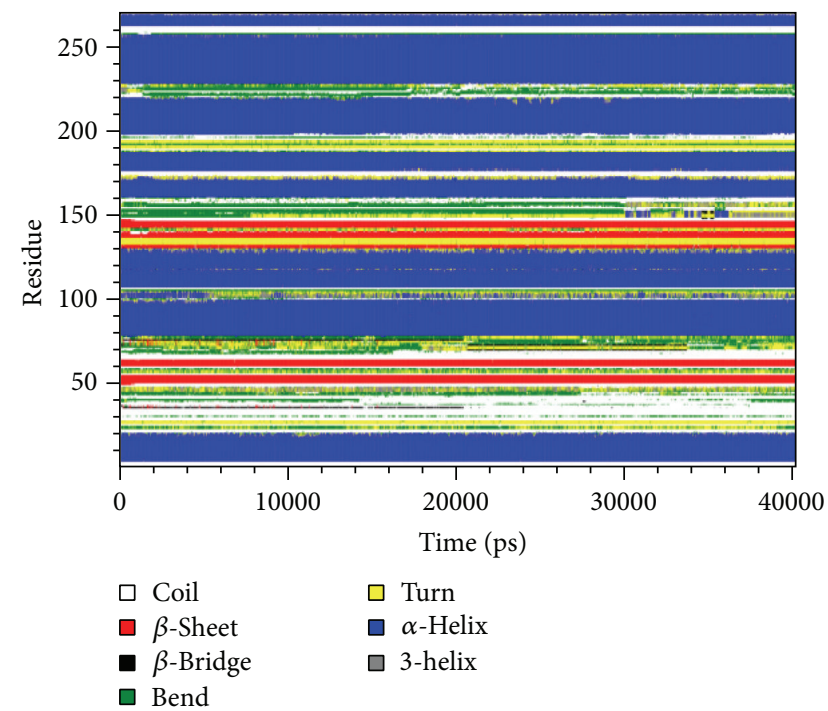

(d)

FIgure 9: Changes of secondary structure in the PXR complex with (a) BEMG, (b) ixerisoside, (c) tangshenoside II, and (d) PNU-142721 during MD simulation. 


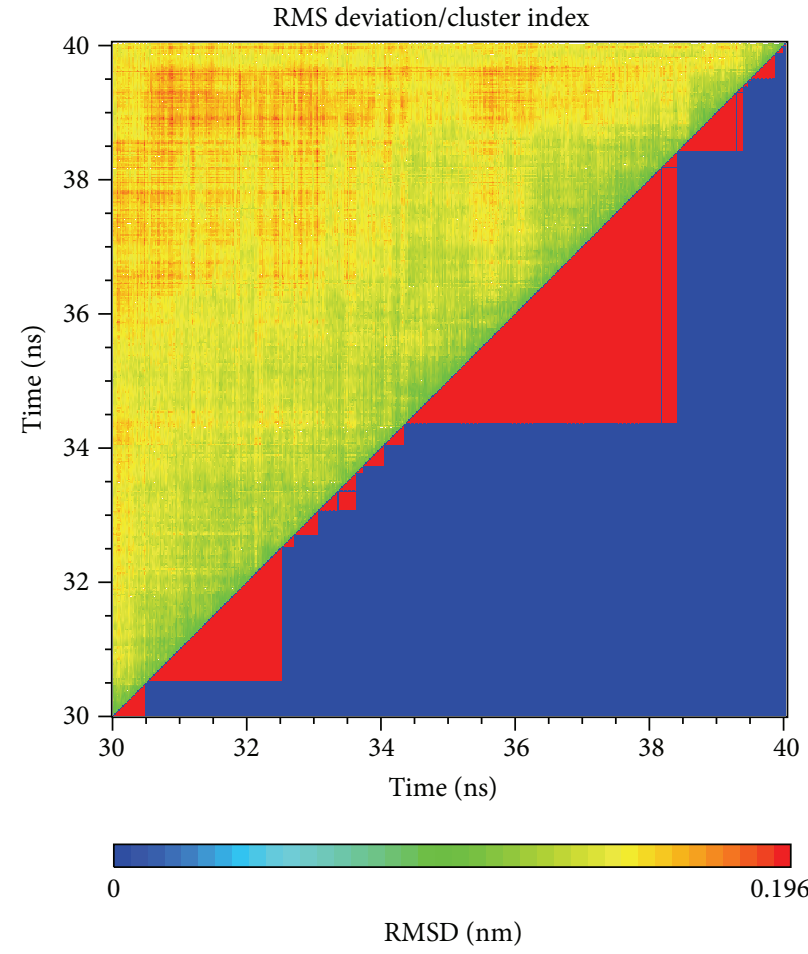

(a)

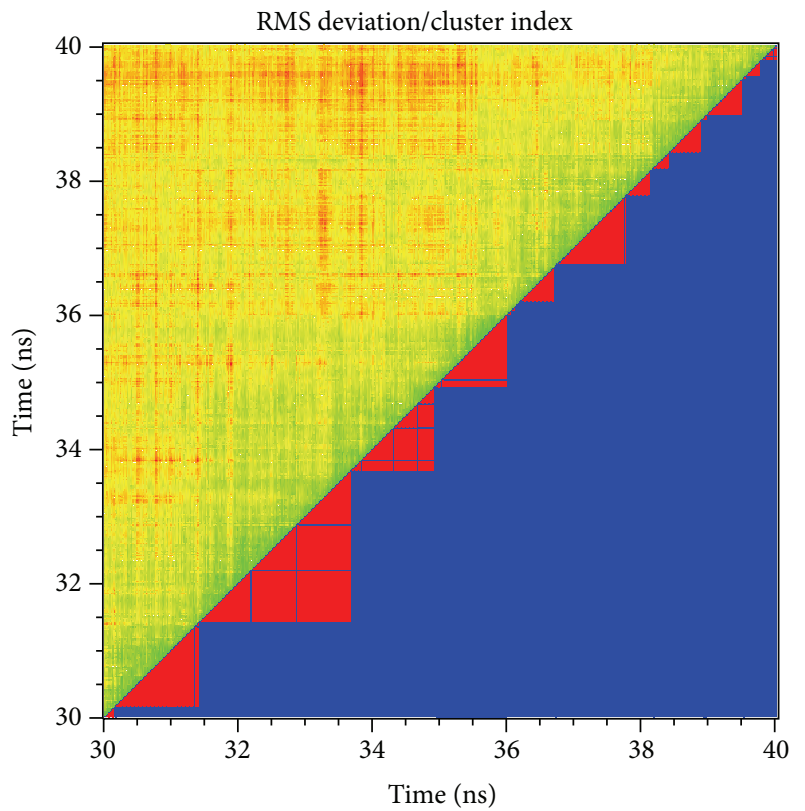$$
0
$$

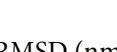

$\operatorname{RMSD}(\mathrm{nm})$

(c)

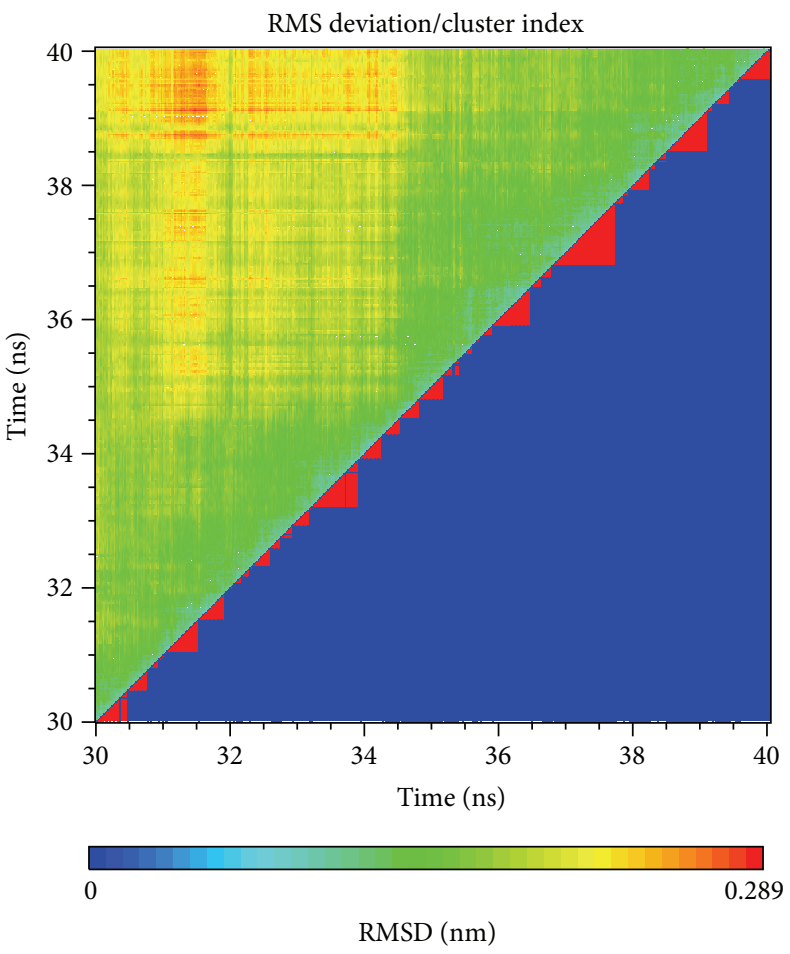

(b)



(d)

FIGURE 10: RMSD matrix and clustering diagram of MD conformations over 30-40 ns for PXR complex with (a) BEMG, (b) ixerisoside, (c) tangshenoside II, and (d) PNU-142721. Clusters were calculated using a cutoff of $0.1 \mathrm{~nm}$. 


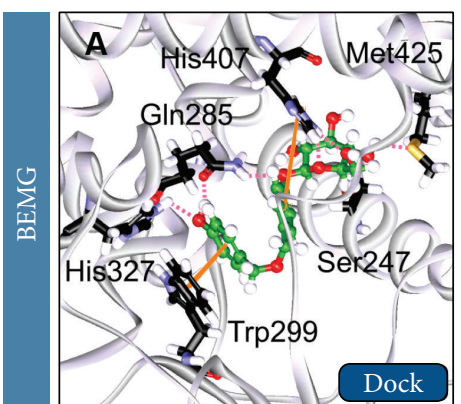

(a)

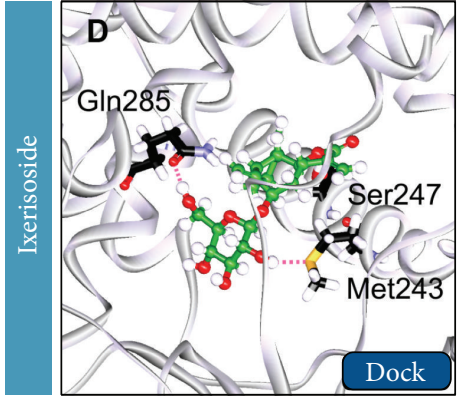

(d)

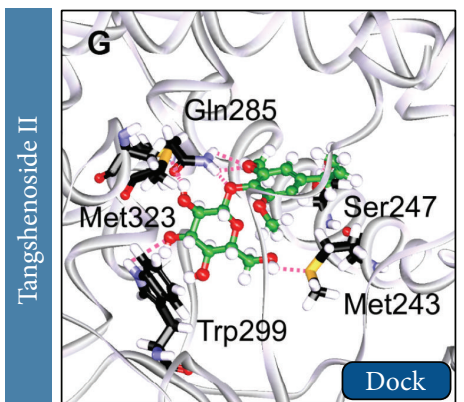

(g)

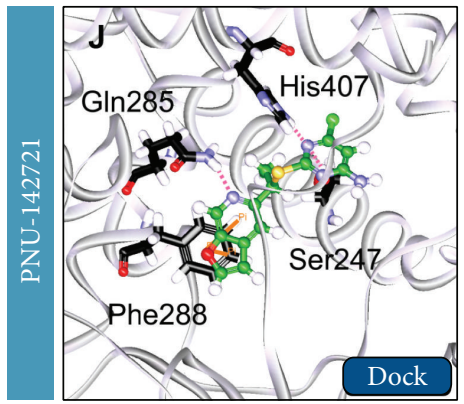

(j)

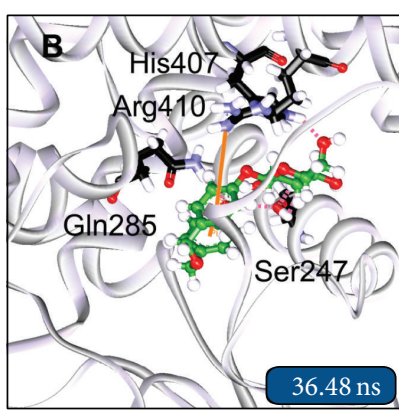

(b)

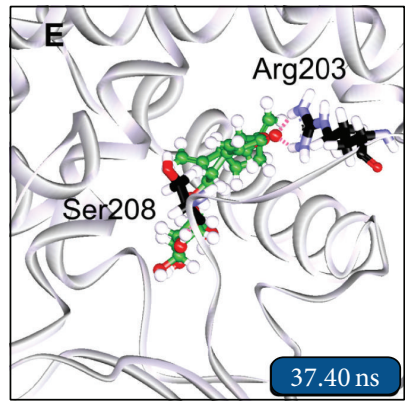

(e)

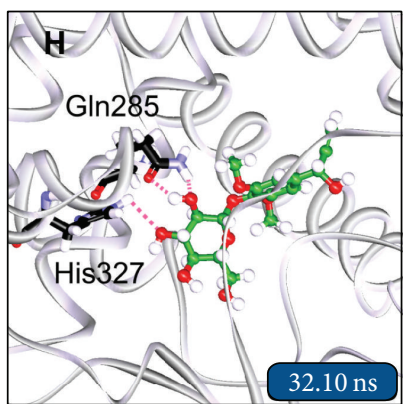

(h)

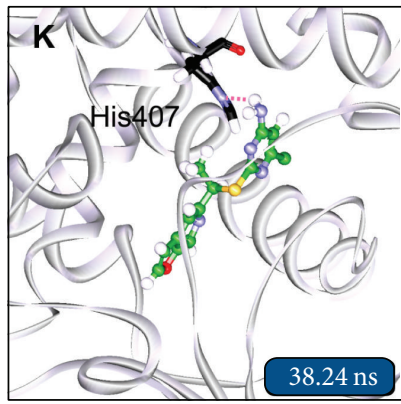

(k)

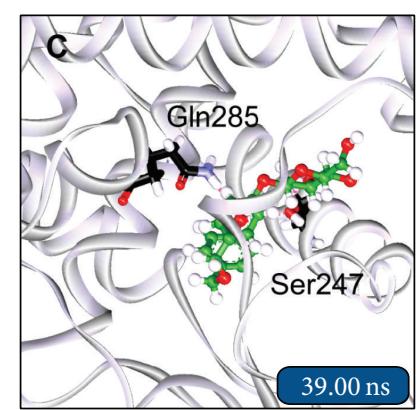

(c)

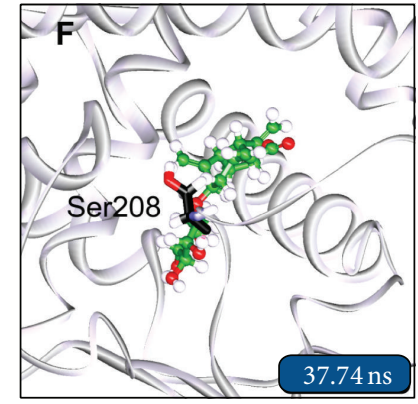

(f)

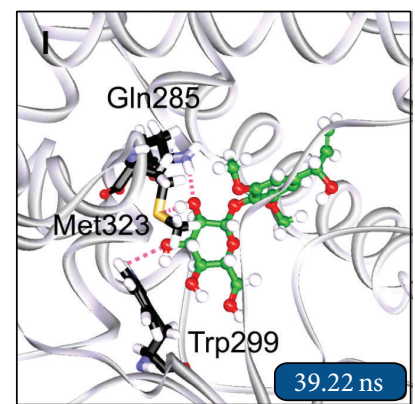

(i)

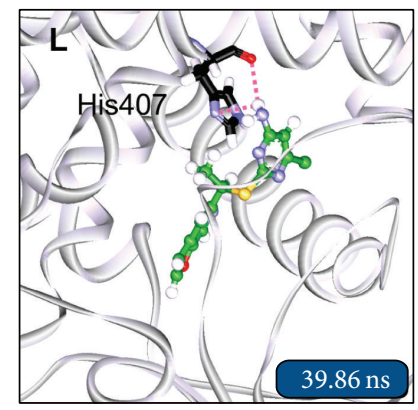

(l)

FIGURE 11: Snapshots of docking pose in docking and MD simulation for PXR complex with (a)-(c) BEMG, (d)-(f) ixerisoside, (g)-(i) tangshenoside II, and (j)-(l) PNU-142721.

changes in the protein structure of PXR induced by the TCM candidates and control, which are tended to stabilize after MD simulation. For the ligand RMSD in Figure 6(a), the value of BMEG tends to stabilize after $2 \mathrm{~ns}$ of MD simulation at approximately $0.21 \mathrm{~nm}$. For the other TCM candidates and control, the ligand RMSD also tends to stabilize after $20 \mathrm{~ns}$ of MD simulation. The variation of radii of gyration for protein and each ligand in Figure 6(b) indicates that each compound may not lead to significant variation to PXR protein under dynamics condition. The slope of the MSD showed in Figure 6(c) indicates that ixerisoside induces larger diffusion changes than others, which has an increase the slope after $20 \mathrm{~ns}$. The variation of solvent accessible surface area (SASA) of PXR protein and each ligand in the complexes 

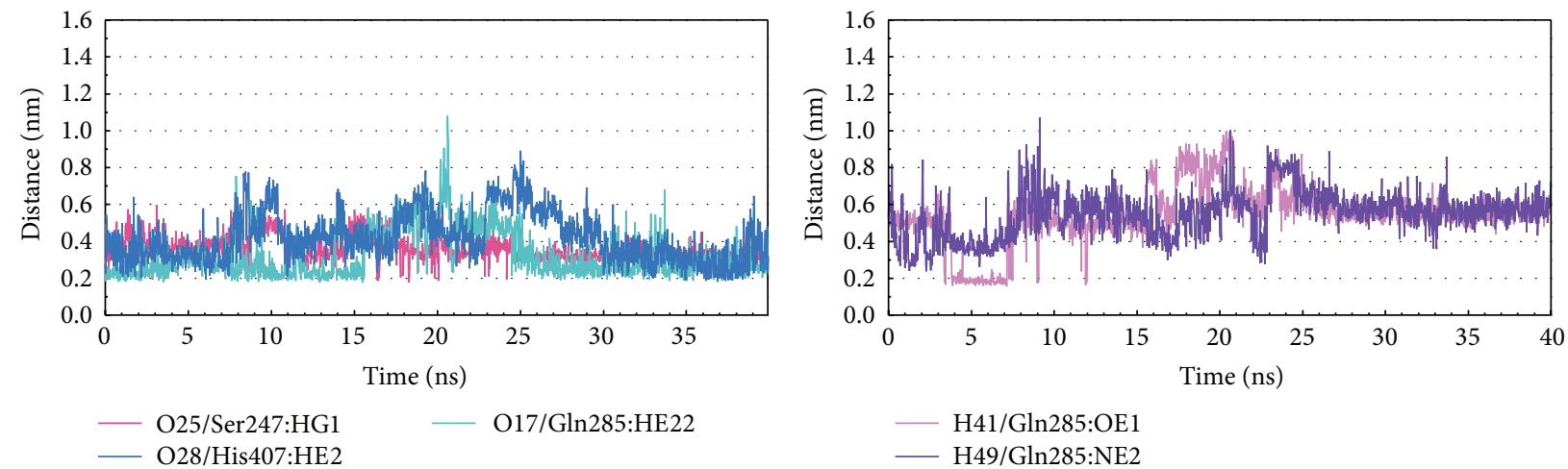

(a)
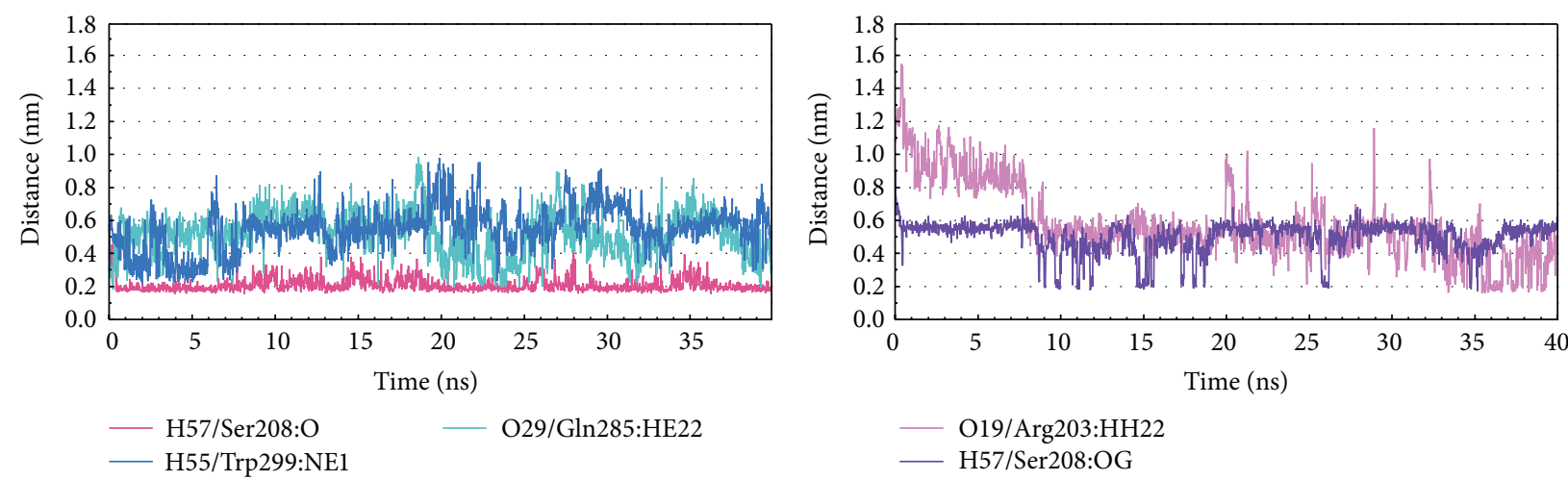

(b)
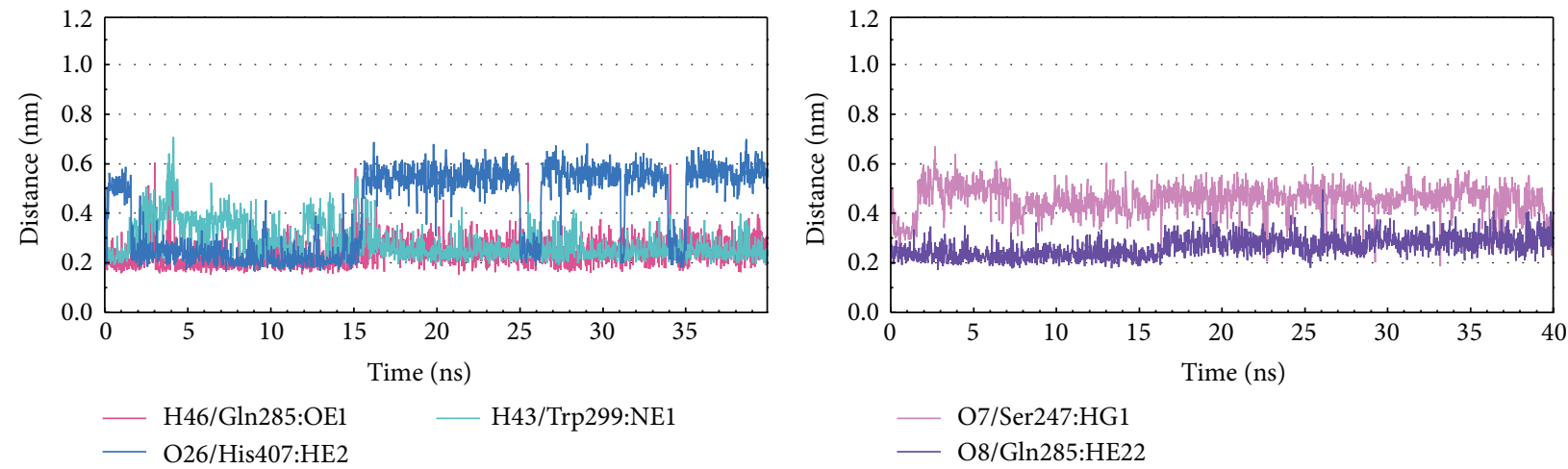

(c)
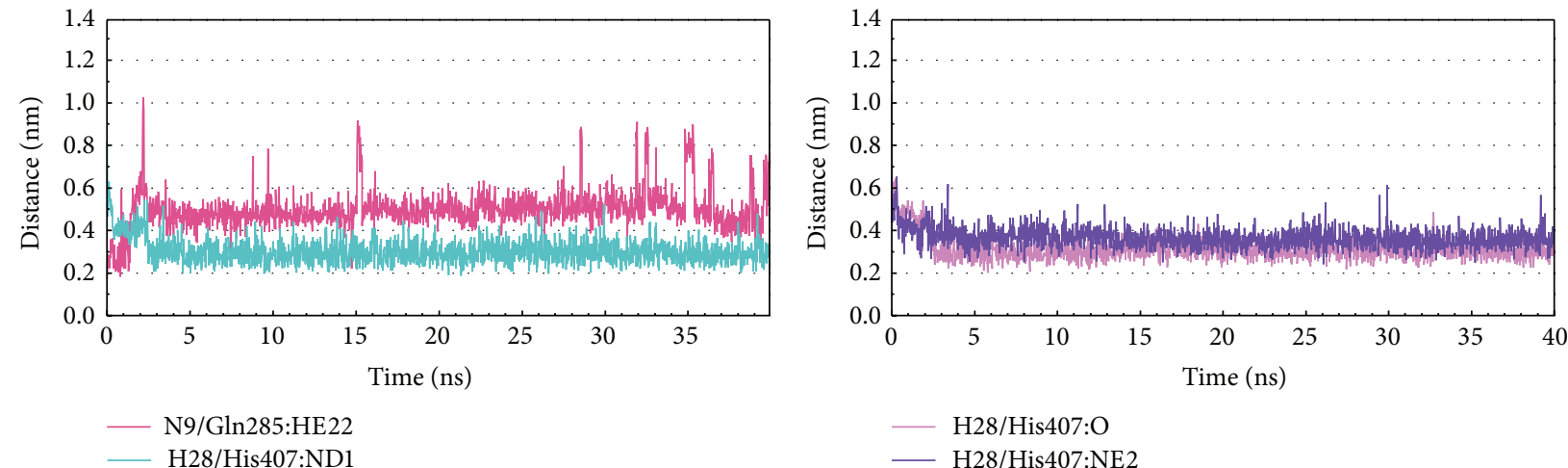

(d)

FIgure 12: Distance variation of H-bonds for PXR complex with (a) BEMG, (b) ixerisoside, (c) tangshenoside II, and (d) PNU-142721 during MD simulation. 


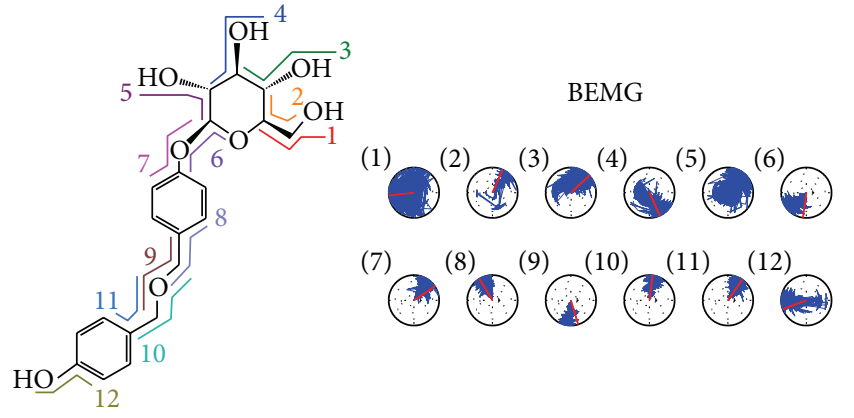

(a)

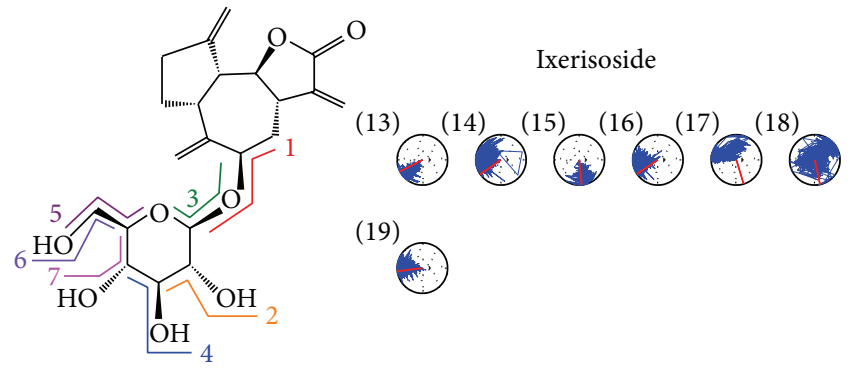

(b)

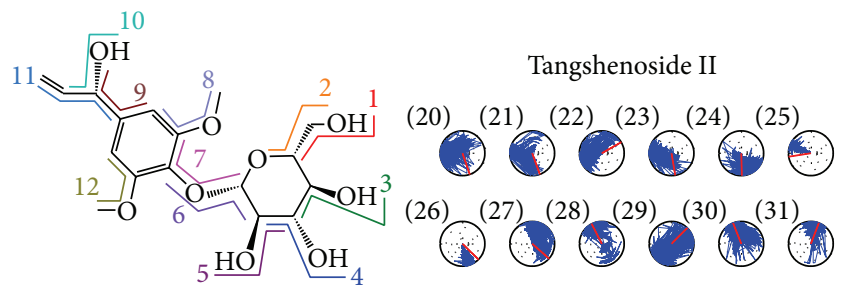

(c)

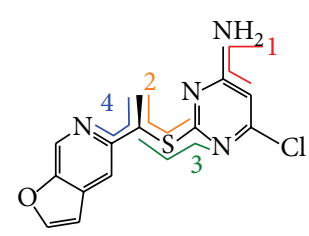

(d)

FIGURE 13: Variation of ligand torsion angles for each PXR complex during $40 \mathrm{~ns}$ of MD simulation.

over $40 \mathrm{~ns}$ of MD simulation is illustrated in Figure 6(d). It shows that there is no significant change in both protein SASA and ligand SASA. The averages of ligand SASA of BEMG, ixerisoside, tangshenoside II, and PNU-142721 are $1.85482 \mathrm{~nm} / \mathrm{NS}^{2}, 0.937577 \mathrm{~nm} / \mathrm{NS}^{2}, 0.499383 \mathrm{~nm} / \mathrm{NS}^{2}$, and $2.896435 \mathrm{~nm} / \mathrm{NS}^{2}$, respectively. For the variation of total energy of each protein complex displayed in Figure 7, there is also no significant change under dynamic conditions. Figure 8 displays the root mean square fluctuation (RMSF) of each residue in each PXR protein complex. The key residues in docking simulation, which are Ser247, Gln285, Phe288, Trp299, and His407, have less flexibility under dynamic conditions. Figure 9 displays the change of secondary structure of PXR protein in each complex. There is no significant change in the secondary structure of PXR protein for each protein complex.

The representative structures of PXR protein complexes after MD simulation were identified by the RMSD values and graphical depiction of the clusters analysis with a RMSD cutoff of $0.1 \mathrm{~nm}$ during 30-40 ns of MD simulation (Figure 10). The docking poses in docking simulation and two representative structures after MD simulation for each PXR protein complex are illustrated in Figure 11. For BEMG, it maintains the H-bonds with Gln285 and Ser247. Ixerisoside forms the H-bond with Ser208 instead of the H-bonds in docking simulation. Tangshenoside II also has stable $\mathrm{H}$ bonds with Gln285, Trp299, and Met323 after MD simulation, as PNU-142721 maintains H-bonds with His407. To discuss the stabilities of $\mathrm{H}$-bonds under dynamics condition, the $\mathrm{H}$-bond occupancy for key residues of PXR protein and variation of each $\mathrm{H}$-bond over $40 \mathrm{~ns}$ of MD simulation are displayed in Table 2 and Figure 12, respectively. BEMG has the stable H-bonds with Ser247, Gln285, and His407 after $30 \mathrm{~ns}$ of $\mathrm{MD}$ simulation. Ixerisoside has stable $\mathrm{H}$-bonds with Ser208 and forms an H-bond with Arg203 instead of Gln285 and Trp299. Tangshenoside II has stable H-bonds with Gln285 and Trp299 and loses the H-bond with Ser247 after 2 ns of MD simulation. For control, PNU-142721, has stable H-bonds with His407. Figure 13 illustrates the variation of torsion angles in each ligand over $40 \mathrm{~ns}$ of MD simulation. The variation of each torsion angle supports the result of distance variation of $\mathrm{H}$-bonds in Figure 12.

\section{Conclusion}

This study aims to investigate the potent TCM candidates for PXR protein. The top three TCM compounds, BEMG, ixerisoside, and tangshenoside II, have displayed higher potent binding affinities than the positive control, PNU142721, in the docking simulation. According to the docking results, the top three candidate compounds and control has hydrophobic contacts with common residues Phe288 and Trp299, and all TCM compounds have hydrophobic contacts with residue Phe281. The docking results indicate that the top three TCM candidate compounds have higher binding affinities than control. In addition, they have $\mathrm{H}$-bonds with key residues Ser247 and Gln285 and hydrophobic contacts with key residues Trp299 and Phe288. The MD simulations are performed to optimize the result of docking simulation and validate the stability of $\mathrm{H}$-bonds between each ligand and PXR protein under dynamic conditions. For the MD simulation, the top three TCM compounds maintain most of interactions with PXR protein, which keep the ligand binding stable in the binding domain. In addition, they have potential bioactivities predicted by the three distinct models. Hence, we propose BEMG and tangshenoside II as potential lead compounds for further study in drug development process with the PXR protein. 
TABLE 1: Docking results and predicted $\mathrm{pEC}_{50}$ for top TCM compounds and PNU-142721.

\begin{tabular}{|c|c|c|c|c|c|c|c|}
\hline \multirow{2}{*}{ Name } & \multirow{2}{*}{$\mathrm{CS}^{*}$} & \multirow{2}{*}{ Dock score } & \multirow{2}{*}{$\begin{array}{l}\text { H-bond forming } \\
\text { residues }\end{array}$} & \multirow{2}{*}{ H-bond quantity } & \multicolumn{3}{|c|}{ Predicted activity ${ }^{*}$} \\
\hline & & & & & SVM $^{*}$ & MLR $^{*}$ & $\mathrm{BNT}^{*}$ \\
\hline $\begin{array}{l}\text { Bis(4-hydroxybenzyl) ether } \\
\text { mono-beta-D-glucopyranoside }\end{array}$ & 11.00 & 100.59 & $\begin{array}{l}\text { Ser247, Gln285, } \\
\text { His327, His } 407\end{array}$ & 6 & 5.17 & 2.92 & 5.29 \\
\hline Ixerisoside & 10.00 & 103.44 & Ser247, Gln285 & 2 & 6.34 & 4.22 & 5.23 \\
\hline Tangshenoside II & 8.00 & 105.556 & $\begin{array}{l}\text { Ser247, Gln285, } \\
\quad \text { Met243 }\end{array}$ & 6 & 6.51 & 3.77 & 4.89 \\
\hline Ruine & 8.00 & 104.085 & Ser247, His407 & 4 & 5.24 & 2.73 & 5.22 \\
\hline Crotalaburnine & 9.00 & 100.181 & Ser247, Gln285 & 3 & 5.62 & 1.70 & 4.50 \\
\hline $\begin{array}{l}\text { Dihydroferulic acid } \\
\text { [3-(4-hydroxy-3-methoxyphenyl) } \\
\text { propionic acid] }\end{array}$ & 9.00 & 98.854 & $\begin{array}{l}\text { Gln285, His327, } \\
\text { Met } 425\end{array}$ & 4 & 6.11 & 2.89 & 4.44 \\
\hline Corchoionoside C & 8.00 & 99.075 & Ser247, Met425 & 2 & 6.36 & 3.10 & 4.64 \\
\hline Beta-D-glucosyl-columbianetin & 8.00 & 98.283 & $\mathrm{G} \ln 285$ & 1 & 6.05 & 3.96 & 5.24 \\
\hline Ethyl rosmarinate & 8.00 & 97.721 & Hisa327, His407 & 2 & 5.91 & 2.94 & 4.63 \\
\hline Persicarin & 7.00 & 102.239 & Ser247, Gln285 & 2 & 7.24 & 9.68 & 5.83 \\
\hline $\begin{array}{l}\text { 6beta,7beta,16beta,17-Tetrahydroxy- } \\
\text { ent-kauranoic } \\
\text { acid }\end{array}$ & 7.00 & 100.892 & $\begin{array}{l}\text { Ser247, Gln285, } \\
\quad \text { His } 407\end{array}$ & 5 & 6.43 & 4.22 & 4.96 \\
\hline Androsin & 7.00 & 99.939 & $\begin{array}{l}\text { Gln285, His } 327, \\
\text { His } 407\end{array}$ & 5 & 6.35 & 3.47 & 4.62 \\
\hline Baihuaqianhuoside & 7.00 & 98.004 & $\begin{array}{l}\text { Ser247, Gln285, } \\
\quad \text { Met243 }\end{array}$ & 3 & 6.08 & 2.77 & 4.51 \\
\hline Eleutheroside B & 7.00 & 97.823 & $\mathrm{Gln} 285$ & 3 & 6.58 & 3.94 & 4.93 \\
\hline Androsin & 6.00 & 102.747 & $\begin{array}{l}\text { Gln285, His } 327, \\
\text { His407 }\end{array}$ & 4 & 6.28 & 3.22 & 4.55 \\
\hline $\begin{array}{l}\text { 4-Hydroxy-3-methoxy- } \\
\text { acetophenone-4-O-beta-D- } \\
\text { glucopyranoside }\end{array}$ & 6.00 & 99.008 & Gln285, His407 & 3 & 6.35 & 3.47 & 4.62 \\
\hline Nortrachelogenin & 6.00 & 98.94 & Gln285, Met425 & 2 & 5.14 & 1.75 & 4.64 \\
\hline $\begin{array}{l}\text { 3-Methoxy-4-beta-D- } \\
\text { glucopyranosyloxypropiophenone }\end{array}$ & 5.00 & 98.645 & $\begin{array}{l}\text { Ser247, Gln285, } \\
\text { His327 }\end{array}$ & 4 & 6.08 & 2.77 & 4.51 \\
\hline Azelaic acid & 3.00 & 102.435 & $\begin{array}{l}\text { Ser247, His327, } \\
\text { His } 407\end{array}$ & 4 & 7.16 & 5.44 & 3.63 \\
\hline Sulfoorientalol D & 3.00 & 100.402 & Gln285, His407 & 3 & 6.59 & 3.90 & 4.42 \\
\hline PNU-142721* & 0 & 46.172 & $\begin{array}{l}\text { Ser247, Gln285, } \\
\text { His407 }\end{array}$ & 1 & 5.72 & 0.54 & 4.10 \\
\hline
\end{tabular}

PNU-142721: control.

CS: consensus score.

SVM: support vector machine.

MLR: multiple linear regression.

BNT: Bayesian network.

Predicted activity: $-\log$ (activity, where activity $=\%$ transactivation of PXR receptor $\times 10 \mu \mathrm{mol} / \mathrm{L})$.

\section{Conflict of Interests}

The authors declared that there is no conflict of interests.

\section{Authors' Contribution}

Kuen-Bao Chen, Hsin-Yi Chen, and Kuan-Chung Chen contributed equally to this paper.

\section{Acknowledgments}

The research was supported by Grants from the National Science Council of Taiwan (NSC102-2325-B039-001 and NSC102-2221-E-468-027-), Asia University (ASIA100-CMU2, ASIA101-CMU-2, and 102-ASIA-07), and China Medical University Hospital (DMR-103-058, DMR-103-001, and DMR-103-096). This study is also supported in part by Taiwan 
TABLE 2: H-bond occupancy for key residues of PXR protein complex with the top three candidates and PNU-142721 over 40 ns molecular dynamics simulation.

\begin{tabular}{|c|c|c|c|c|c|c|c|}
\hline \multirow{2}{*}{ Ligand } & \multirow{2}{*}{ H-bond } & \multirow{2}{*}{ Ligand atom } & \multirow{2}{*}{ Amino acid } & \multicolumn{3}{|c|}{ Distance $(\mathrm{nm})$} & \multirow{2}{*}{ Occupancy (\%) } \\
\hline & & & & Max. & Min. & Average & \\
\hline \multirow{12}{*}{ BEMG } & 1 & $\mathrm{O} 25$ & Ser247:HG1 & 0.62 & 0.18 & 0.36 & $12.85 \%$ \\
\hline & 2 & $\mathrm{O} 26$ & Ser247:HG1 & 0.90 & 0.19 & 0.49 & $7.60 \%$ \\
\hline & 3 & O17 & Ser247:HG1 & 0.91 & 0.18 & 0.48 & $4.40 \%$ \\
\hline & 4 & $\mathrm{O} 27$ & Ser247:HG1 & 0.86 & 0.19 & 0.47 & $4.00 \%$ \\
\hline & 5 & $\mathrm{O} 17$ & Gln285:HE22 & 1.08 & 0.17 & 0.32 & $59.90 \%$ \\
\hline & 6 & $\mathrm{O} 27$ & Gln285:HE22 & 0.89 & 0.18 & 0.36 & $31.45 \%$ \\
\hline & 7 & $\mathrm{H} 41$ & Gln285:OE1 & 1.00 & 0.16 & 0.54 & $9.75 \%$ \\
\hline & 8 & H49 & Gln285:NE2 & 1.07 & 0.24 & 0.55 & $1.95 \%$ \\
\hline & 9 & $\mathrm{O} 28$ & His407:HE2 & 0.89 & 0.18 & 0.42 & $18.95 \%$ \\
\hline & 10 & O19 & His407:HE2 & 0.88 & 0.20 & 0.56 & $4.20 \%$ \\
\hline & 11 & $\mathrm{O} 25$ & His407:HE2 & 0.61 & 0.21 & 0.40 & $5.75 \%$ \\
\hline & 12 & H52 & His407:ND1 & 0.78 & 0.20 & 0.47 & $1.80 \%$ \\
\hline \multirow{9}{*}{ Ixerisoside } & 1 & H57 & Ser208:O & 0.57 & 0.15 & 0.21 & $95.70 \%$ \\
\hline & 2 & O19 & Arg203:HH22 & 1.55 & 0.16 & 0.58 & $7.15 \%$ \\
\hline & 3 & H57 & Ser208:OG & 0.90 & 0.17 & 0.50 & $6.85 \%$ \\
\hline & 4 & $\mathrm{O} 19$ & Arg203:HH12 & 1.66 & 0.16 & 0.77 & $2.45 \%$ \\
\hline & 5 & $\mathrm{O} 29$ & Gln285:HE22 & 0.99 & 0.18 & 0.52 & $6.45 \%$ \\
\hline & 6 & H55 & Gln285:OE1 & 0.99 & 0.18 & 0.60 & $3.45 \%$ \\
\hline & 7 & $\mathrm{O} 22$ & Gln285:HE22 & 0.91 & 0.21 & 0.65 & $0.50 \%$ \\
\hline & 8 & $\mathrm{H} 55$ & Trp299:NE1 & 0.98 & 0.21 & 0.55 & $5.50 \%$ \\
\hline & 9 & H56 & Trp299:NE1 & 0.69 & 0.23 & 0.45 & $1.55 \%$ \\
\hline \multirow{10}{*}{ Tangshenoside II } & 1 & $\mathrm{H} 46$ & Gln285:OE1 & 0.61 & 0.15 & 0.25 & $84.20 \%$ \\
\hline & 2 & $\mathrm{O} 8$ & Gln285:HE22 & 0.50 & 0.17 & 0.26 & $78.75 \%$ \\
\hline & 3 & $\mathrm{O} 23$ & Gln285:HE22 & 0.51 & 0.17 & 0.26 & $76.70 \%$ \\
\hline & 4 & O9 & Gln285:HE22 & 0.57 & 0.20 & 0.38 & $13.40 \%$ \\
\hline & 5 & O7 & Gln285:HE22 & 0.75 & 0.23 & 0.47 & $1.00 \%$ \\
\hline & 6 & O7 & Ser247:HG1 & 0.67 & 0.19 & 0.46 & $1.10 \%$ \\
\hline & 7 & $\mathrm{O} 26$ & Ser247:HG1 & 0.85 & 0.19 & 0.59 & $0.30 \%$ \\
\hline & 8 & $\mathrm{H} 43$ & Trp299:NE1 & 0.71 & 0.19 & 0.28 & $71.05 \%$ \\
\hline & 9 & H45 & Trp299:NE1 & 0.69 & 0.22 & 0.44 & $6.50 \%$ \\
\hline & 10 & $\mathrm{O} 26$ & His407:HE2 & 0.70 & 0.17 & 0.42 & $38.05 \%$ \\
\hline \multirow{4}{*}{ PNU-142721 } & 1 & N9 & Gln285:HE22 & 1.03 & 0.17 & 0.50 & $2.40 \%$ \\
\hline & 2 & $\mathrm{H} 28$ & His407:ND1 & 0.82 & 0.19 & 0.30 & $54.55 \%$ \\
\hline & 3 & $\mathrm{H} 28$ & His407:O & 1.05 & 0.20 & 0.31 & $44.55 \%$ \\
\hline & 4 & $\mathrm{H} 28$ & His407:NE2 & 0.65 & 0.24 & 0.37 & $5.60 \%$ \\
\hline
\end{tabular}

H-bond occupancy cutoff: $0.3 \mathrm{~nm}$.

Department of Health Clinical Trial and Research Center of Excellence (DOH102-TD-B-111-004), Taiwan Department of Health Cancer Research Center of Excellence (MOHW103TD-B-111-03), and CMU under the Aim for Top University Plan of the Ministry of Education, Taiwan.

\section{References}

[1] A. S. Go, D. Mozaffarian, V. L. Roger et al., "Heart disease and stroke statistics-2013 update: a report from the American Heart Association," Circulation, vol. 127, no. 1, Article ID e6e245, 2013.
[2] C. A. Ihunnah, M. Jiang, and W. Xie, "Nuclear receptor PXR, transcriptional circuits and metabolic relevance," Biochimica et Biophysica Acta: Molecular Basis of Disease, vol. 1812, no. 8, pp. 956-963, 2011.

[3] K. E. Swales and D. Bishop-Bailey, "The potential use of the pregnane X receptor in cardiovascular therapy," Expert Review of Cardiovascular Therapy, vol. 10, no. 9, pp. 1079-1082, 2012.

[4] A. R. Pries and W. M. Kuebler, "Normal endothelium," Handbook of Experimental Pharmacology, no. 176, pp. 1-40, 2006.

[5] B. Hennig, G. Reiterer, Z. Majkova, E. Oesterling, P. Meerarani, and M. Toborek, "Modification of environmental toxicity by nutrients: implications in atherosclerosis," Cardiovascular Toxicology, vol. 5, no. 2, pp. 153-160, 2005. 
[6] Y. M. Leung, K. L. Wong, S. W. Chen et al., "Down-regulation of voltage-gated $\mathrm{Ca} 2+$ channels in $\mathrm{Ca} 2+$ store-depleted rat insulinoma RINm5F cells," BioMedicine, vol. 3, no. 3, pp. 130139, 2013.

[7] Y. Jiang, X. Li, W. Yang et al., "PKM2 regulates chromosome segregation and mitosis progression of tumor cells," Molecular Cell, vol. 53, no. 1, pp. 75-87, 2014.

[8] V. Janssens and J. Goris, "Protein phosphatase 2A: a highly regulated family of serine/threonine phosphatases implicated in cell growth and signalling," The Biochemical Journal, vol. 353, no. 3, pp. 417-439, 2001.

[9] M. A. Leissring, E. Malito, S. Hedouin et al., "Designed inhibitors of insulin-degrading enzyme regulate the catabolism and activity of insulin," PLoS ONE, vol. 5, no. 5, Article ID e10504, 2010.

[10] K.-P. Su, "Inflammation in psychopathology of depression: clinical, biological, and therapeutic implications," BioMedicine, vol. 2, no. 2, pp. 68-74, 2012.

[11] C.-L. Jao, S.-L. Huang, and K.-C. Hsu, "Angiotensin I-converting enzyme inhibitory peptides: inhibition mode, bioavailability, and antihypertensive effects," BioMedicine, vol. 2, no. 4, pp. 130-136, 2012.

[12] S. A. Kliewer, B. Goodwin, and T. M. Willson, "The nuclear pregnane X receptor: a key regulator of xenobiotic metabolism," Endocrine Reviews, vol. 23, no. 5, pp. 687-702, 2002.

[13] A. Geick, M. Eichelbaum, and O. Burk, "Nuclear receptor response elements mediate induction of intestinal MDR1 by rifampin," Journal of Biological Chemistry, vol. 276, no. 18, pp. 14581-14587, 2001.

[14] K. E. Swales, R. Moore, N. J. Truss et al., "Pregnane X receptor regulates drug metabolism and transport in the vasculature and protects from oxidative stress," Cardiovascular Research, vol. 93, no. 4, pp. 674-681, 2012.

[15] G. Bertilsson, J. Heidrich, K. Svensson et al., "Identification of a human nuclear receptor defines a new signaling pathway for CYP3A induction," Proceedings of the National Academy of Sciences of the United States of America, vol. 95, no. 21, pp. 12208$12213,1998$.

[16] S. A. Kliewer, J. T. Moore, L. Wade et al., "An orphan nuclear receptor activated by pregnanes defines a novel steroid signaling pathway," Cell, vol. 92, no. 1, pp. 73-82, 1998.

[17] B. Blumberg, W. Sabbagh Jr., H. Juguilon et al., "SXR, a novel steroid and xenobiotic-sensing nuclear receptor," Genes and Development, vol. 12, no. 20, pp. 3195-3205, 1998.

[18] L. M. Tompkins and A. D. Wallace, "Mechanisms of cytochrome P450 induction," Journal of Biochemical and Molecular Toxicology, vol. 21, no. 4, pp. 176-181, 2007.

[19] R. E. Watkins, P. R. Davis-Searles, M. H. Lambert, and M. R. Redinbo, "Coactivator binding promotes the specific interaction between ligand and the pregnane X receptor," Journal of Molecular Biology, vol. 331, no. 4, pp. 815-828, 2003.

[20] R. E. Watkins, G. B. Wisely, L. B. Moore et al., "The human nuclear xenobiotic receptor PXR: structural determinants of directed promiscuity," Science, vol. 292, no. 5525, pp. 2329-2333, 2001.

[21] R. E. Watkins, S. M. Noble, and M. R. Redinbo, "Structural insights into the promiscuity and function of the human pregnane X receptor," Current Opinion in Drug Discovery and Development, vol. 5, no. 1, pp. 150-158, 2002.

[22] J. Orans, D. G. Teotico, and M. R. Redinbo, "The nuclear xenobiotic receptor pregnane $\mathrm{X}$ receptor: recent insights and new challenges," Molecular Endocrinology, vol. 19, no. 12, pp. 28912900, 2005.

[23] S. D. Shenoy, T. A. Spencer, N. A. Mercer-Haines et al., "Induction of CYP3A by 2,3-oxidosqualene:lanosterol cyclase inhibitors is mediated by an endogenous squalene metabolite in primary cultured rat hepatocytes," Molecular Pharmacology, vol. 65, no. 5, pp. 1302-1312, 2004.

[24] E. G. Schuetz, C. Brimer, and J. D. Schuetz, "Environmental xenobiotics and the antihormones cyproterone acetate and spironolactone use the nuclear hormone pregnenolone $\mathrm{X}$ receptor to activate the CYP3A23 hormone response element," Molecular Pharmacology, vol. 54, no. 6, pp. 1113-1117, 1998.

[25] C. Y.-C. Chen, "A novel integrated framework and improved methodology of computer-aided drug design," Current Topics in Medicinal Chemistry, vol. 13, no. 9, pp. 965-988, 2013.

[26] W. I. Tou, S.-S. Chang, C.-C. Lee, and C. Y.-C. Chen, "Drug design for neuropathic pain regulation from traditional Chinese medicine," Scientific Reports, vol. 3, p. 844, 2013.

[27] K. C. Chen, Y. R. Jian, M. F. Sun et al., "Investigation of silent information regulator 1 (Sirt1) agonists from Traditional Chinese Medicine," Journal of Biomolecular Structure \& Dynamics, vol. 31, no. 11, pp. 1207-1218, 2013.

[28] H.-J. Huang, H. W. Yu, C.-Y. Chen et al., "Current developments of computer-aided drug design," Journal of the Taiwan Institute of Chemical Engineers, vol. 41, no. 6, pp. 623-635, 2010.

[29] C. Y.-C. Chen, "Weighted equation and rules-a novel concept for evaluating protein-ligand interaction," Journal of Biomolecular Structure and Dynamics, vol. 27, no. 3, pp. 271-282, 2009.

[30] K.-C. Chen and C. Yu-Chian Chen, "Stroke prevention by traditional Chinese medicine? A genetic algorithm, support vector machine and molecular dynamics approach," Soft Matter, vol. 7, no. 8, pp. 4001-4008, 2011.

[31] K.-C. Chen, K.-W. Chang, H.-Y. Chen, and C. Y.-C. Chen, "Traditional Chinese medicine, a solution for reducing dual stroke risk factors at once?" Molecular BioSystems, vol. 7, no. 9, pp. 2711-2719, 2011.

[32] T.-T. Chang, K.-C. Chen, K.-W. Chang et al., "In silico pharmacology suggests ginger extracts may reduce stroke risks," Molecular BioSystems, vol. 7, no. 9, pp. 2702-2710, 2011.

[33] Y. A. Tsou, K. C. Chen, S. S. Chang, Y. R. Wen, and C. Y. Chen, "A possible strategy against head and neck cancer: in silico investigation of three-in-one inhibitors," Journal of Biomolecular Structure \& Dynamics, vol. 31, no. 12, pp. 13581369, 2013.

[34] Y.-A. Tsou, K.-C. Chen, H.-C. Lin, S.-S. Chang, and C. Y.-C. Chen, "Uroporphyrinogen decarboxylase as a potential target for specific components of Traditional Chinese Medicine: a virtual screening and molecular dynamics study," PLoS ONE, vol. 7, no. 11, Article ID e50087, 2012.

[35] S.-C. Yang, S.-S. Chang, H.-Y. Chen, and C. Y.-C. Chen, "Identification of potent EGFR inhibitors from TCM Database@Taiwan," PLoS Computational Biology, vol. 7, no. 10, Article ID e1002189, 2011.

[36] C.-Y. Chen and C. Y.-C. Chen, "Insights into designing the dual-targeted HER2/HSP90 inhibitors," Journal of Molecular Graphics and Modelling, vol. 29, no. 1, pp. 21-31, 2010.

[37] K.-C. Chen, M.-F. Sun, S.-C. Yang et al., "Investigation into potent inflammation inhibitors from Traditional Chinese Medicine," Chemical Biology and Drug Design, vol. 78, no. 4, pp. 679-688, 2011. 
[38] K. C. Chen, S. S. Chang, F. J. Tsai, and C. Y. Chen, "Han ethnicity-specific type 2 diabetic treatment from traditional Chinese medicine?" Journal of Biomolecular Structure \& Dynamics, vol. 31, no. 11, pp. 1219-1235, 2013.

[39] H.-J. Huang, K.-J. Lee, H. W. Yu, H.-Y. Chen, F.-J. Tsai, and C. Y.-C. Chen, "A novel strategy for designing the selective PPAR agonist by the "Sum of activity" model," Journal of Biomolecular Structure and Dynamics, vol. 28, no. 2, pp. 187-200, 2010.

[40] K.-C. Chen, S.-S. Chang, H.-J. Huang, T.-L. Lin, Y.-J. Wu, and C. Y.-C. Chen, "Three-in-one agonists for PPAR-a, PPAR- $\gamma$, and PPAR-d from traditional Chinese medicine," Journal of Biomolecular Structure and Dynamics, vol. 30, no. 6, pp. 662683, 2012.

[41] S.-S. Chang, H.-J. Huang, and C. Y.-C. Chen, "Two birds with one stone? Possible dual-targeting H1N1 inhibitors from traditional Chinese medicine," PLoS Computational Biology, vol. 7, no. 12, Article ID e1002315, 2011.

[42] H. J. Huang, Y. R. Jian, and C. Y. Chen, "Traditional Chinese medicine application in HIV: an in silico study," Journal of Biomolecular Structure \& Dynamics, vol. 32, no. 1, pp. 1-12, 2014.

[43] H.-C. Tang and C. Y.-C. Chen -C, "Investigation of the novel lead of melanocortin 1 receptor for pigmentary disorders," Evidence-Based Complementary and Alternative Medicine, vol. 2014, Article ID 254678, 13 pages, 2014.

[44] H.-J. Huang, C.-C. Lee, and C. Y.-C. Chen, "Pharmacological chaperone design for reducing risk factor of Parkinson's disease from traditional Chinese medicine," Evidence-Based Complementary and Alternative Medicine, vol. 2014, Article ID 830490, 12 pages, 2014.

[45] H. Y. Chen, S. S. Chang, Y. C. Chan, and C. Y. Chen, "Discovery of novel insomnia leads from screening traditional Chinese medicine database," Journal of Biomolecular Structure \& Dynamics, vol. 32, no. 5, pp. 776-791, 2014.

[46] W. I. Tou and C. Y. Chen, "May disordered protein cause serious drug side effect?" Drug Discovery Today, vol. 19, no. 4, pp. 367372, 2013.

[47] C. Y.-C. Chen and W. I. Tou, "How to design a drug for the disordered proteins?” Drug Discovery Today, vol. 18, no. 19-20, pp. 910-915, 2013.

[48] Y. Cheng and M. R. Redinbo, "Activation of the human nuclear xenobiotic receptor PXR by the reverse transcriptase-targeted anti-HIV drug PNU-142721," Protein Science, vol. 20, no. 10, pp. 1713-1719, 2011.

[49] B. Xue, R. L. Dunbrack, R. W. Williams, A. K. Dunker, and V. N. Uversky, "PONDR-FIT: a meta-predictor of intrinsically disordered amino acids," Biochimica et Biophysica Acta: Proteins and Proteomics, vol. 1804, no. 4, pp. 996-1010, 2010.

[50] B. R. Brooks, R. E. Bruccoleri, B. D. Olafson et al., "CHARMM: a program for macromolecular energy minimization and dynamics calculations," Journal of Computational Chemistry, vol. 4, pp. 187-217, 1983.

[51] C. Y.-C. Chen, “TCM Database@Taiwan: the world's largest traditional Chinese medicine database for drug screening in silico," PLoS ONE, vol. 6, no. 1, Article ID e15939, 2011.

[52] C. A. Lipinski, F. Lombardo, B. W. Dominy, and P. J. Feeney, "Experimental and computational approaches to estimate solubility and permeability in drug discovery and development settings," Advanced Drug Delivery Reviews, vol. 46, no. 1-3, pp. 3-26, 2001.

[53] C. M. Venkatachalam, X. Jiang, T. Oldfield, and M. Waldman, "LigandFit: a novel method for the shape-directed rapid docking of ligands to protein active sites," Journal of Molecular Graphics and Modelling, vol. 21, no. 4, pp. 289-307, 2003.

[54] K. Zimmermann, M. D. Wittman, M. G. Saulnier et al., "SAR of PXR transactivation in benzimidazole-based IGF-1R kinase inhibitors," Bioorganic and Medicinal Chemistry Letters, vol. 20, no. 5, pp. 1744-1748, 2010.

[55] D. Rogers and A. J. Hopfinger, "Application of genetic function approximation to quantitative structure-activity relationships and quantitative structure-property relationships," Journal of Chemical Information and Computer Sciences, vol. 34, no. 4, pp. 854-866, 1994.

[56] C.-C. Chang and C.-J. Lin, "LIBSVM: a library for support vector machines," ACM Transactions on Intelligent Systems and Technology, vol. 2, no. 3, article 27, 2011.

[57] B. Hess, C. Kutzner, D. van der Spoel, and E. Lindahl, "GRGMACS 4: algorithms for highly efficient, load-balanced, and scalable molecular simulation," Journal of Chemical Theory and Computation, vol. 4, no. 3, pp. 435-447, 2008.

[58] V. Zoete, M. A. Cuendet, A. Grosdidier, and O. Michielin, "SwissParam: a fast force field generation tool for small organic molecules," Journal of Computational Chemistry, vol. 32, no. 11, pp. 2359-2368, 2011.

[59] R. Fletcher, Optimization, Academic Press, New York, NY, USA, 1969.

[60] L. G. Jian Yin, Modern Study of Chinese Drugs, Xueyuan Press, Beijing, China, 1993, (Chinese).

[61] X. Xiong, X. Yang, W. Liu et al., "Banxia baizhu tianma decoction for essential hypertension: a systematic review of randomized controlled trials," Evidence-based Complementary and Alternative Medicine, vol. 2012, Article ID 271462, 10 pages, 2012.

[62] H. W. Zhang, J. Tong, G. Zhou, H. Jia, and J. Y. Jiang, “Tianma Gouteng Yin Formula for treating primary hypertension," Cochrane Database of Systematic Reviews, vol. 6, Article ID CD008166, 2012.

[63] W. Kisiel and K. Zielińska, "Guaianolides from Cichorium intybus and structure revision of Cichorium sesquiterpene lactones," Phytochemistry, vol. 57, no. 4, pp. 523-527, 2001.

[64] P. N. Pushparaj, H. K. Low, J. Manikandan, B. K. H. Tan, and C. H. Tan, "Anti-diabetic effects of Cichorium intybus in streptozotocin-induced diabetic rats," Journal of Ethnopharmacology, vol. 111, no. 2, pp. 430-434, 2007.

[65] A. J. Atta, T. A. Elkoly, S. M. Mouneir, G. Kamel, N. A. Alwabel, and S. Zaher, "Hepatoprotective effect of methanol extracts of Zingiber officinale and Cichorium intybus," Indian Journal of Pharmaceutical Sciences, vol. 72, no. 5, pp. 564-570, 2010.

[66] D. Song, G.-X. Chou, G.-Y. Zhong, and Z.-T. Wang, "Two new phenylpropanoid derivatives from codonopsis tangshen OLIV," Helvetica Chimica Acta, vol. 91, no. 10, pp. 1984-1988, 2008. 

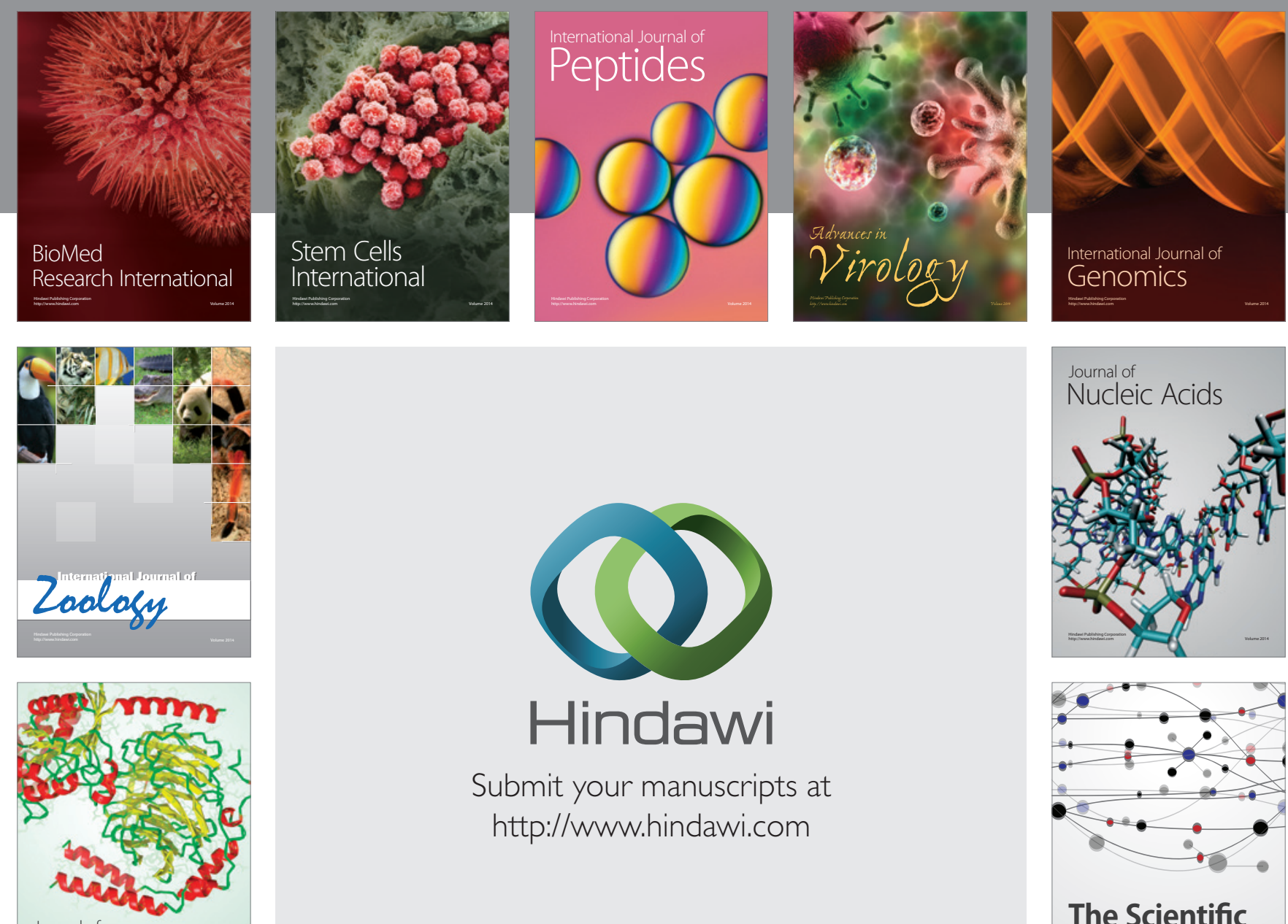

Submit your manuscripts at

http://www.hindawi.com

Journal of
Signal Transduction
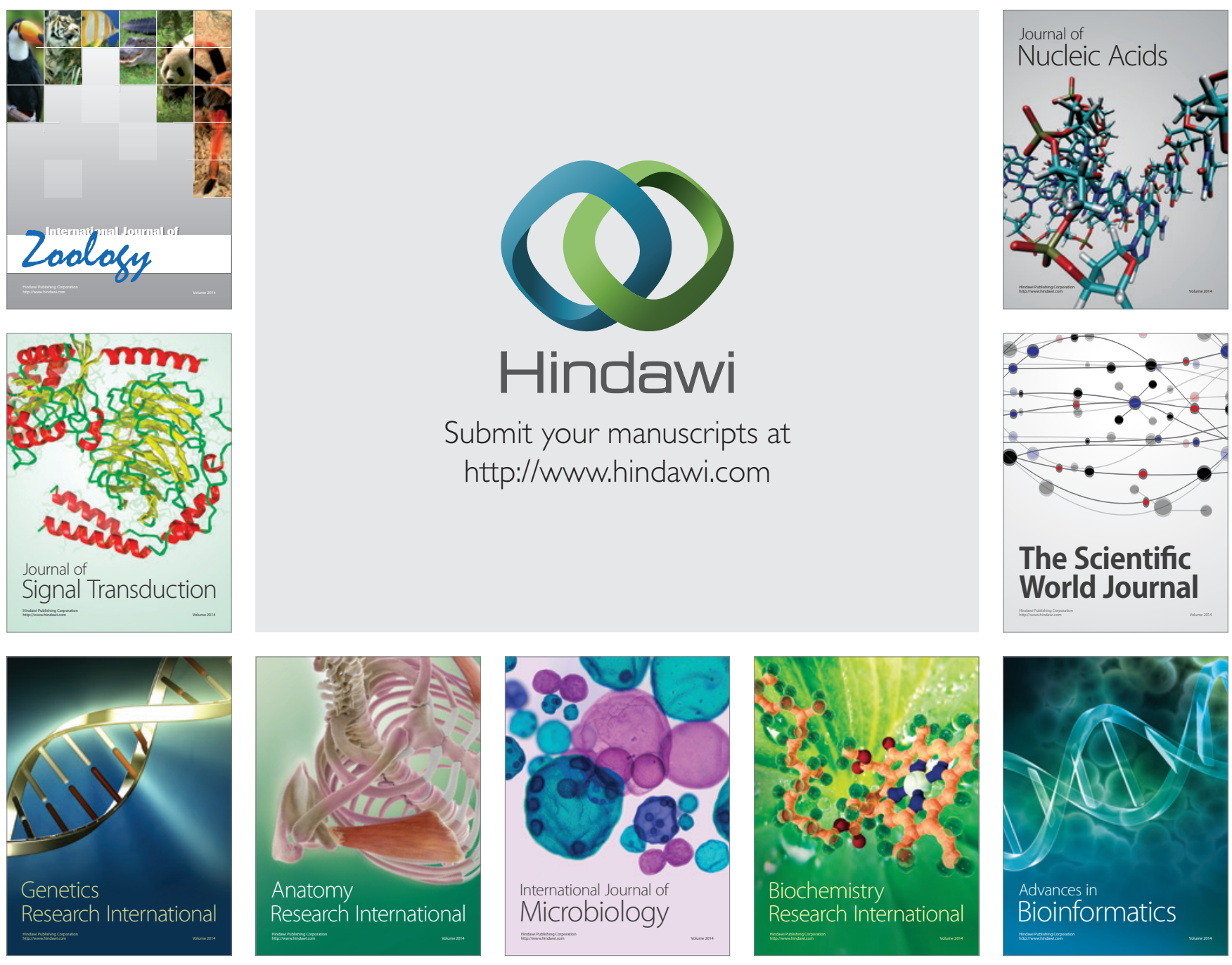

The Scientific World Journal
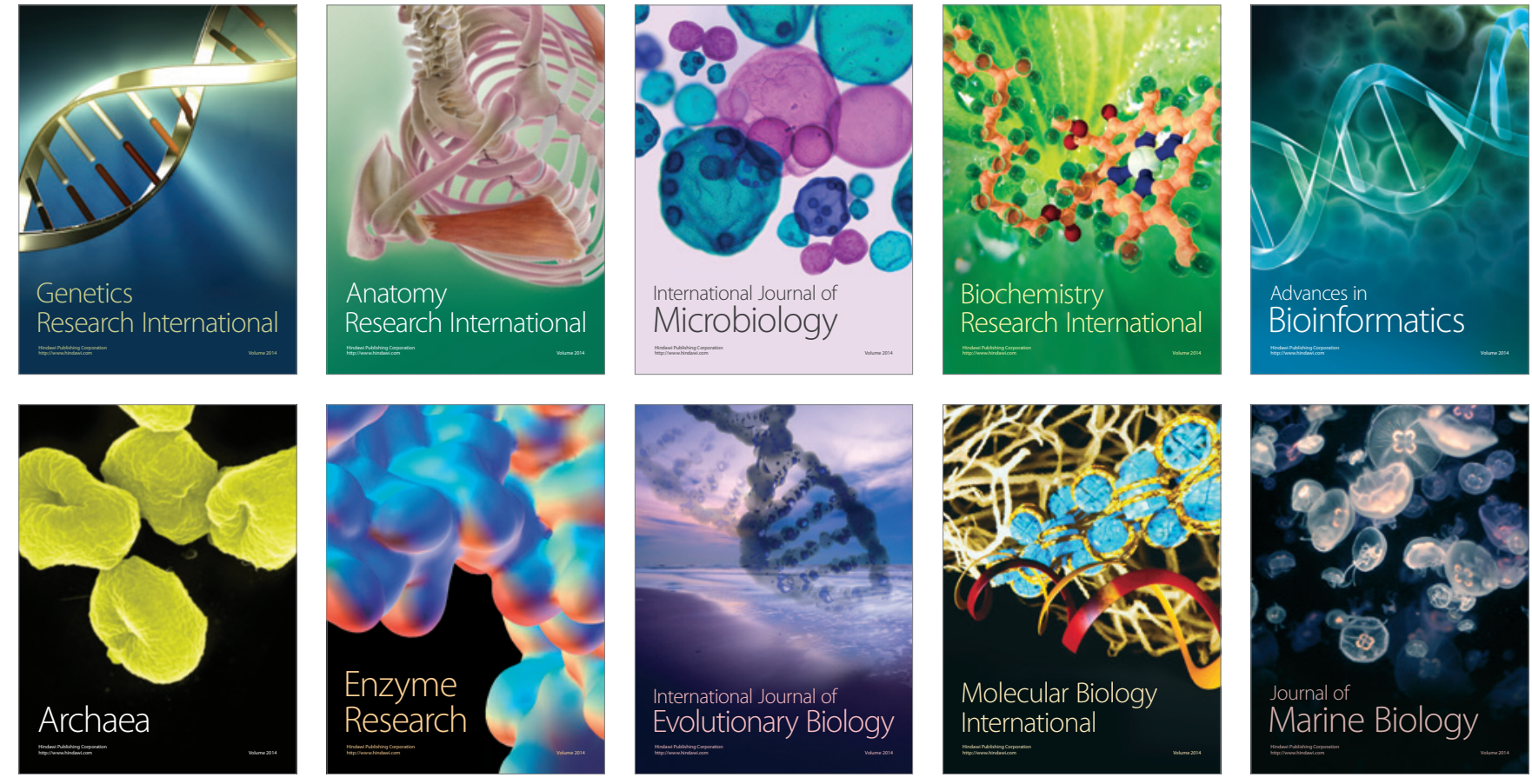